\title{
Deciphering channel networks from aeromagnetic potential field data: the case of the North Sea Quaternary tunnel valleys
}

\author{
S. Brahimi ${ }^{\oplus},{ }^{1}$ P. Le Maire, ${ }^{1,2,}{ }^{*}$ J.F. Ghienne ${ }^{1}$ and M. Munschy ${ }^{1}$ \\ ${ }^{1}$ Institut de Physique du Globe de Strasbourg, UMR7516, CNRS-University of Strasbourg/EOST, 1 rue Blessig, 67084 Strasbourg Cedex, France. \\ E-mail: sonia.brahimi@unistra.fr; brahimisonia@hotmail.com \\ ${ }^{2}$ Cardem, 7 Rue de l'Uranium, 67800 Bischheim, France
}

Accepted 2019 October 27. Received 2019 October 22; in original form 2019 April 30

\begin{abstract}
SUMMAR Y
High-resolution magnetic data and potential field methods have been used to perform a detailed analysis of networks of late Quaternary subglacially cut tunnel valleys (central Viking Graben, Norwegian sector of the North Sea). High-frequency, ribbon-like, sinuous, paired magnetic anomalies interpreted to be the signature of tunnel valleys are identified. Such magnetic anomalies have 1-8 nT amplitudes and reflect a magnetic susceptibility contrast between valley infills and the host sediments. Fractional vertical derivative and horizontal gradient transforms provide the best control on the accurately delineation of tunnel valleys by plotting automatically the extrema. The 2-D forward modelling is a very effective approach to determine the geometric parameters and magnetic susceptibility of the modelled valleys. It allows us to determine the finite-width flat horizontal thin geometry as the most appropriate simple geometry to simulate the magnetic anomaly linked to a channel structure. The application of Euler deconvolution using complex algebra allows us to substantiate the structural index $(n=1.5)$ for simple palaeovalley geometries and to determine fair valley depth estimates.
\end{abstract}

Key words: Magnetic propreties; Magnetic anomalies: modelling and interpretation; Europe.

\section{INTRODUCTION}

The magnetic method is most often used to image the structure of the basement, either in outcropping rocks (Bournas et al. 2003; Martelat et al. 2014) or below a sedimentary cover (Babaahmadi \& Rosenbaum 2015; Brahimi et al. 2018). The magnetic method can also provide valuable information on smaller-scale sedimentary bodies, buried archaeological remains (Gavazzi et al. 2017) or pipe and power networks, but only if high-resolution data are available and if a sufficient, measurable magnetic contrast does exist between the studied structures and the host rocks. A limited number of publications has addressed magnetic characterization of buried palaeochannels or palaeovalley of fluvial (Mackey et al. 2000; Jessell et al. 2015) or glacial (Parker Gay 2004; Fichler et al. 2005; Olesen et al. 2010) origin. In most cases, such studies have used basic high-pass filters for simple aeromagnetic mapping of the channel structures and no detailed magnetic analysis has been carried out on the characterization of their physical property and geometric parameters (width, depth, incision thickness). In this study, we take advantage of a high-resolution aeromagnetic data set acquired in the North Sea (Norwegian sector) in order to perform a detailed

\footnotetext{
* Now at: BRGM, DGR/GAT, 3 av. Claude-Guillemin, BP 36009, 45060 Orléans Cedex 2, France
}

magnetic analysis on an intricate system of superimposed tunnel valleys and, more generally, to show the efficiency of potential field methods for the geometric characterization of channel structures.

In northern Europe, tunnel valleys may constitute hydrocarbon accumulations in the offshore (Bauer \& Fichler 2002; Andreassen et al. 2007; Kristensen \& Huuse 2012) and are significant groundwater reservoirs onshore (Gabriel et al. 2003; Huuse et al. 2003, Kluiving et al. 2003; BurVal Working Group 2006; Kirsch 2006). Shallow gas accumulation in valley fills are also a hazard to petroleum drilling operations in pre-Pleistocene strata (Bauer \& Fichler 2002; Andreassen et al. 2007; Kristensen \& Huuse 2012). Tunnel valley mapping is thus crucial and is routinely performed on the basis of 2-D and 3-D seismic surveys (Praeg 1996 ; Huuse \& LykkeAndersen 2000; Fichler et al. 2005; Moreau et al. 2012; Van der Vegt et al. 2012; Stewart et al. 2013) though other geophysical methods have also been deployed, such as electromagnetism (Auken et al. 2003, Jørgensen et al. 2003; Jørgensen \& Sandersen 2006; Steuer et al. 2009; Høyer et al. 2015) and gravimetry (Lindner et al. 2000; Gabriel 2006). All these methods revealed that the physical properties (seismic velocity, electrical conductivity, susceptibility, density, porosity) characterizing the tunnel valley infills generally differ from those of surrounding sediments. Though the valley infills include a wide range of sedimentary facies varying from sandy to clayey sediments (Stewart et al. 2012), the magnetization contrast only depends on the proportion of ferromagnetic minerals in the 
infill relative to that in the host sediments. High susceptibility values characterize the North Sea glaciomarine clays including magnetite and/or haematite, Ti-Fe oxide and pyrite suggested to be derived from the crystalline basement on mainland Norway (Britt \& Olesen 1996). Then, a tunnel valley filled in by glaciomarine clays or, conversely, a tunnel valley cut in glaciomarine clays - provided the valley infill is characterized by low susceptibilities - is expected to produce well-defined magnetic anomalies.

The aim of this study is to investigate the physical and geometrical properties of channel structures of a particular case study, that is, the North Sea tunnel valleys, essentially by exploiting high-resolution aeromagnetic data. First, fractional vertical derivative and horizontal gradient transforms well be used in order to identify high-frequency magnetic anomalies. Secondly, 2-D forward modelling will be performed for basement-related long wavelength anomalies in order to properly extract the signature of high-frequency magnetic anomalies, most of which will be demonstrated to be linked to tunnel valleys, buried or not. The high-frequency magnetic anomalies will then be modelled initially assuming the sources of the anomalies are simple geometric objects, prior to progressively complexifying the models. This step is crucial in order to define a common inversion model for the kind of anomalies generated by a channel structure. Finally, the Euler deconvolution, which is an automatic depth estimation method, is applied by using complex algebra to propose estimates of the depth and location of the tunnel valleys. Results from published seismic surveys and bathymetric data will be used in order to better constrain and calibrate our method of magnetic characterization, here specifically developed for tunnel valleys but that should be also advantageously applied to the mapping of a variety of buried channel structures in other Quaternary to pre-Quaternary case studies.

\section{GEOLOGICAL SETTING}

\subsection{Regional framework}

The North Sea is characterized by a three-armed rift system comprising the Viking Graben, the Inner and Outer Moray Firth basins and the Central Graben (Fig. 1; Ziegler 1990; Gowers et al. 1993; Evans 2003). After an initial Permian-Triassic event, the current configuration of the North Sea basin essentially originates from the late Jurassic-early Cretaceous rifting event (Fig. 2). It was followed by regional-scale thermal subsidence, uplift and denudation of the Scandinavian, British and NW European landmasses during the late Cretaceous and Cenozoic time (Riis 1996; Faleide et al. 2002; Rasmussen et al. 2005; Gibbard \& Lewin 2016; Westaway 2017; Lee et al. 2018), yet extensional events and episodes of basin inversion also occurred in the Palaeogene and early Neogene (Ziegler 1992; Huuse et al. 2001; Anell et al. 2011; Jarsve et al. 2014). This polyphase development has accommodated hundreds of metres sediments supplied from the uplifted margins (Fig. 2). Finally, in the central North Sea, the depocentre corresponds to a narrow graben of $50 \mathrm{~km}$ wide - the Viking Graben - bounded by high shoulders averaging 2-3 km below sea level (Isaksen et al. 2002; Evans 2003). This thickness interval corresponds to the thick Palaeogene and Quaternary successions, overlapping both shoulders (Fig. 2). Overlying the late Miocene to Pliocene Utsira Formation, up to $1 \mathrm{~km}$ thick Quaternary sediments are ascribed to the Naust sequence equivalent to the Aberdeen Fm. in the UK sector (Galloway 2002; Ottesen et al. 2014). The early Quaternary sediments comprise prograding depositional units predominantly sourced from the east (Scandinavia) before the incision of the Norwegian Channel (Ottesen et al., 2016, 2018). They are separated from the overlying glaciation-related sediments that include the here-studied tunnel valley networks by the Upper Regional Unconformity (URU; Ottesen et al. 2014). The corresponding sediments are upper Middle and Late Pleistocene in age since the Bruhnes-Matuyama Magnetochron reversal at $0.78 \mathrm{Ma}$ is thought to be located close to the URU (Stoker et al. 1983; Sejrup et al. 1987; Ottesen et al. 2014).

\subsection{Tunnel valleys}

Tunnel valleys correspond to elongated depressions initially cut by subglacial meltwater flows into glaciated sedimentary lowlands and basins. They are generally oriented parallel to ice-flow direction, are positioned close to retreating ice sheet margins, and may display an undulating thalweg (Huuse \& Lykke-Andersen 2000; Kehew et al. 2012; Van der Vegt et al. 2012). The tunnel valley infill may show a wide range of sedimentary facies including till, glaciofluvial sands and gravels, glaciolacustrine and glaciomarine muds (Stewart et al. 2012) It depends on the timing of infill, in particular whether they are filled simultaneously with the gradual retreat of the ice front margin (Kristensen et al. 2008; Benvenuti \& Moscariello 2016) or subsequently during the deglaciation development (Jørgensen \& Sandersen 2006).

Several generations of tunnel valley networks have been delineated in the North Sea, in (Fichler et al. 2005) and around the study area (Lonergan et al. 2006; Stewart \& Lonergan 2011, Stewart et al. 2013), the two later generations being related to the Elsterian and Weichselian glaciations (Ehlers 1996; Huuse \& Lykke-Andersen 2000; van der Vegt et al. 2012; Benvenuti \& Moscariello 2016). Some of the youngest (Weichselian) tunnel valleys have been left underfilled and are evidenced on bathymetric data sets (Jørgensen \& Sandersen 2006; Sandersen et al. 2009). In the adjacent UK sector where tunnel valleys have been extensively mapped, they generally have width and length ranging between 0.3 and $3 \mathrm{~km}$ and 10 and $50 \mathrm{~km}$, respectively, the largest ones reaching $7 \mathrm{~km}$ in width. Individual valley fills range from 80 to $200 \mathrm{~m}$ (Lonergan et al. 2006; Stewart \& Lonergan 2011; Stewart et al. 2013). Dips of the tunnel valley margins are commonly $10^{\circ}$, reaching in some cases $30^{\circ}$. In the study area (Fig. 1): (i) the seabed is 100-160 m deep, the largest depths corresponding to an underfilled tunnel valleys; (ii) most of the tunnel valley networks are buried beneath a $45-180 \mathrm{~m}$ thick sediment cover, using an average velocity of $1800 \mathrm{~m} \mathrm{~s}^{-1}$ for Quaternary formations (Ottesen et al. 2014); (iii) the incision depth of individual tunnel valleys was ranging between 45 and $180 \mathrm{~m}$ (Fichler et al. 2005; Ottesen et al. 2014), but, owing to subsidence, the thalweg depth of the oldest (mid-Pleistocene) tunnel valleys reaches $450 \mathrm{~m}$ (including the sea-water column).

\section{MAGNETIC DATA}

High-resolution aeromagnetic data were acquired by TGS-Nopec in 1994 (Amarok 1994) over the central North Sea (Norwegian sector). The survey, approximately $100 \mathrm{~km} \times 100 \mathrm{~km}$, was flown at an elevation of $100 \mathrm{~m}$ above the sea surface and the flight path was oriented N-S, with spacing of $200 \mathrm{~m}$ for the in-lines and $600 \mathrm{~m}$ for the tie-lines. The International Geomagnetic Reference Field (IGRF90) was subtracted from the data (Amarok 1994). As indicated in the TGS-NOPEC report (Amarok 1994), statistical levelling was applied to the magnetic measurements and has allowed to reduce the initial miss-ties from 20.3 to $0.1 \mathrm{nT}$. Those errors may be related 


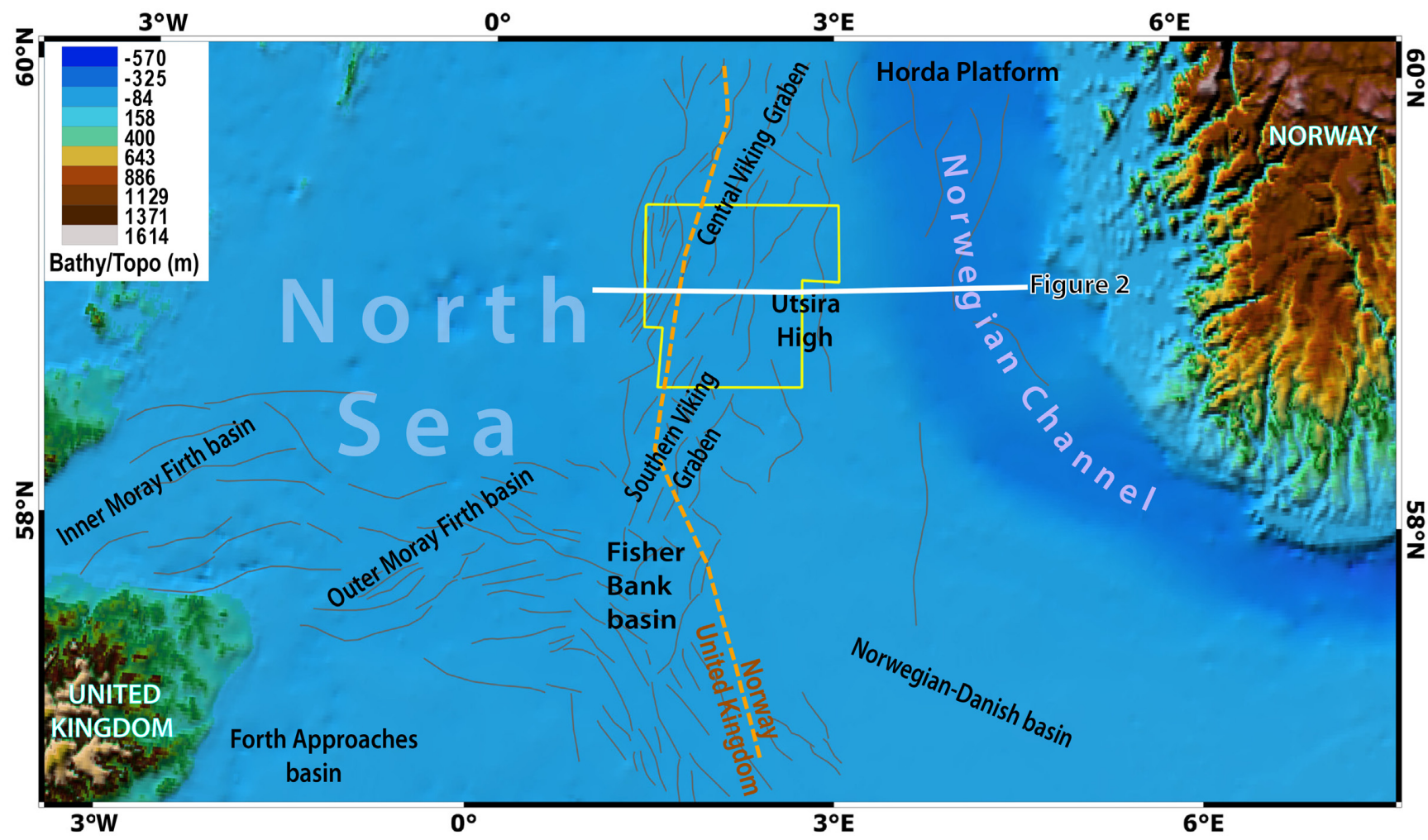

Figure 1. Location of the Viking Graben in the framework of the North Sea. The basemap combines the General Bathymetric Chart of the Ocean grid (GEBCO_2014, Weatherall et al. 2015, http://www.gebco.net) and ETOPO1_bedrock global relief model (Amante \& Eakins 2009); yellow rectangle shows the cover of the magnetic survey. Grey lines correspond to main structural lineaments from Evans (2003).

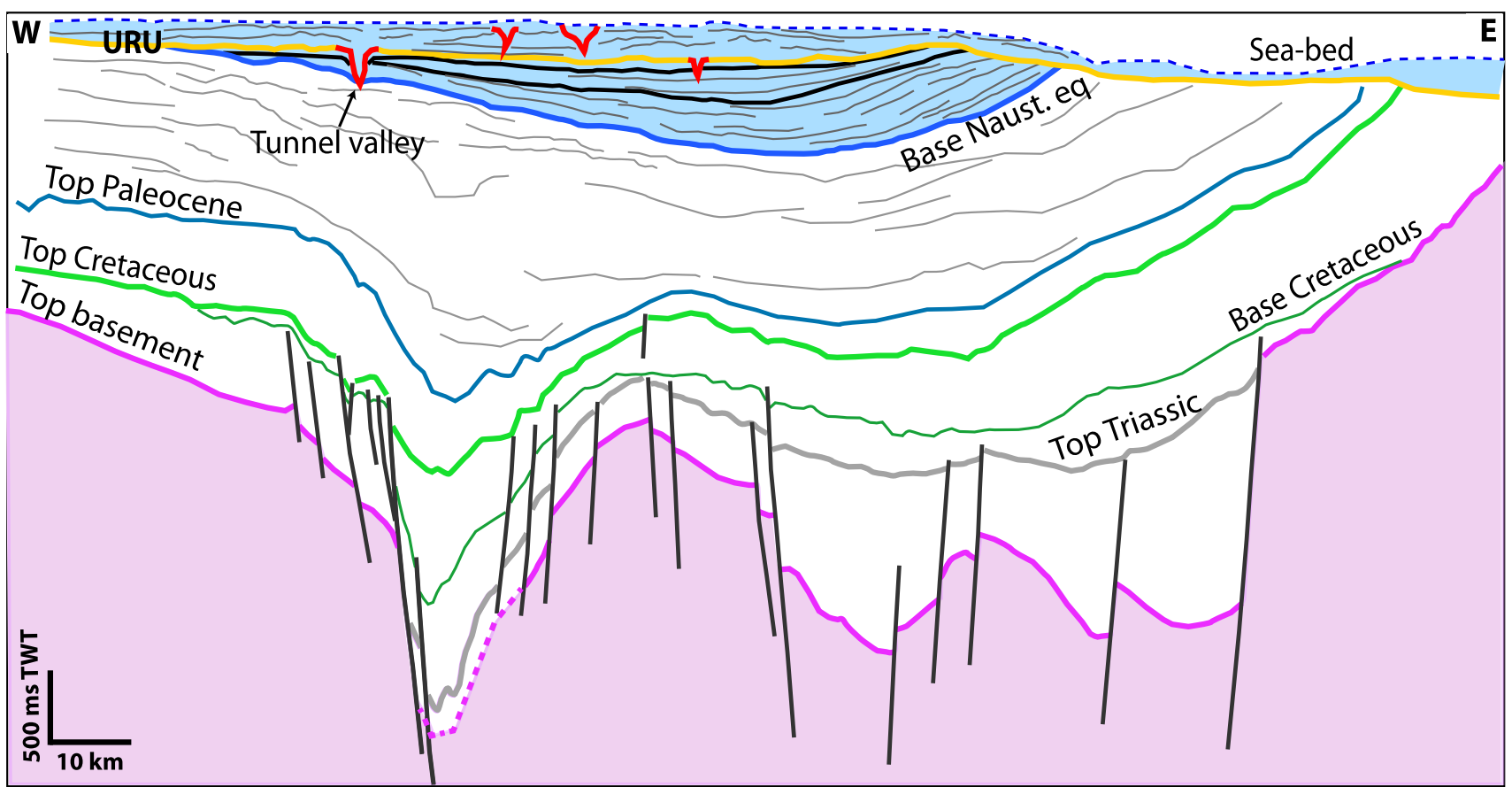

Figure 2. Geological cross-section across the central Viking Graben (compiled from Ottesen et al. 2014 and Evans 2003; see Fig. 1 for location). Note that mid to upper Pleistocene tunnel valleys (in red) have incised down to the early Quaternary sediments beneath the Upper Regional Unconformity (yellow line; Stewart et al. 2013; Ottesen et al., 2014, 2018). URU: Upper Regional Unconformity. 
to the corrections of magnetic base station, lag and heading corrections. We have calculated the grid data with a node spacing of $100 \mathrm{~m}$, by using the gridded method based on the Gridfit function (D'Errico 2010). The obtained Total Magnetic Intensity map (TMI) shows at first order long-wavelength magnetic anomalies ranging from -163 to $160 \mathrm{nT}$, and some weak, superimposed high-frequency anomalies (Fig. 3a).

\section{METHODS}

We use a software of the laboratory, APPLIMAG, for the processing and interpretation of magnetic data. MODGM2D and GMSYS (Oasis montaj 2018) software are used for the 2-D forward modelling, based on the method of Talwani \& Heitzler (1964). APPLIMAG and $M O D G M 2 D$ software are scripts using MATLAB software (MathWorks 2015, http://www.mathworks.com).

In order to accurately delineate the high-frequency magnetic anomalies that are generated by the tunnel valleys, fractional vertical derivative and horizontal gradient transforms are computed. Both transforms are applied to the reduced to the pole magnetic anomaly (RTP) map. Initially, the RTP is applied to the data in order to eliminate the skewness of the anomalies related to the directions of magnetization and regional magnetic field (Baranov 1957). The application of the RTP consists in making vertical the magnetization and regional magnetic field vectors. For the direction of magnetization, we consider that the magnetization is induced, therefore parallel to the regional magnetic field. Knowing that there is only a small contribution of remnant magnetization (i.e. low $Q$-values) in most Cenozoic sediments in Mid Norway, they are largely dominated by induced magnetization (Mørk et al. 2002). The reduced map is calculated using a geomagnetic field with an inclination of $71.21^{\circ} \mathrm{N}$ and a declination of $4.98^{\circ} \mathrm{W}$. Owing to the fact that the study area is located at high-latitude, no major lateral displacement or distortion of magnetic anomalies is observed.

Fractional derivative is calculated using the RTP of the TMI map (Cooper \& Cowan 2003), using the following formula in the spectral domain

$$
\left(a u+b v+i c \sqrt{u^{2}+v^{2}}\right)^{n}
$$

with $(u, v)$ the spatial frequencies in the north and east directions, $(a, b, c)$ the coordinates of the unit vector of derivation and $n$ a real number for $n$-order derivation or integration, $n$ positive for derivation.

The horizontal gradient transform is also applied to the data (Fig. 3b), which allows us to locate the maximum over the edges of the source bodies. This method requires the calculation of the two fractional horizontal derivatives of the TMI map ( $a=1, b=0$, $c=0$ and $a=0, b=1, c=0$ and $n$ equal to 1.7 in eq. 1) and then the modulus map is computed (Grauch \& Cordell 1987) in the spatial domain as

$$
\sqrt{\left(\frac{\partial^{n} T}{\partial^{n} x}\right)^{2}+\left(\frac{\partial^{n} T}{\partial^{n} y}\right)^{2}}
$$

with $T$ the RTP of the TMI map and $n$ the order of derivation

We thus use the method of Blakely \& Simpson (1986) to plot the maxima in map view, that is, on the order 1.7 horizontal gradient map (Fig. 3b). This provides an automatic method for delineating the curvilinear magnetic lineations.

2-D forward models are calculated for deep and shallow structures. First, long wavelength magnetic anomalies are modelled to identify the original causative sources. It enables the extraction of the magnetic signal of the high-frequency anomalies. Secondly, models are calculated for local high frequencies that are generated by the channel structures, in order to characterize their geometries and magnetic properties. Inversion models first use simple geometries and then increasingly complex ones.

Euler deconvolution (Thompson 1982) allows us to estimate the depth of a tunnel valley using magnetic data. This method determines the location and depth of the source in the least-squares sense, without assumption for susceptibility but assuming a structural index value. Assuming 2-D geometries, TMI along magnetic profiles can be transformed to complex magnetic anomaly (CMA) using complex algebra (Le Maire \& Munschy 2018). The CMA functions is a generalization of the 2-D analytic signal theory using complex algebra (Nabighian 1972) and Le Maire \& Munschy (2018) have shown that CMA is a homogeneous function of degree $n$ (Thompson 1982) depending on the geometry, that is,

$\mathrm{CMA}(t c)=t^{n} \mathrm{CMA}(c)$

with $c=c_{x}+\mathrm{i} c_{z}$ the complex coordinate.

The consequence of the homogeneity is the Euler's equation

$(c-a) \cdot \mathrm{CMA}^{(1)}=-n \mathrm{CMA}^{(0)}$

with $a=a_{x}+\mathrm{i} a_{z}$ the localization of the source, $n$ the structural index (Thompson 1982) and $\mathrm{CMA}^{(1)}$ corresponds to the complex derivative of $\mathrm{CMA}^{(0)}$.

If we rearrange the terms of eq. (4), we obtain

$a=c+n \frac{\mathrm{CMA}^{(0)}}{\mathrm{CMA}^{(1)}}$.

Thus, the application of Euler's deconvolution to complex algebra shows a simple ratio between the function $\mathrm{CMA}^{(0)}(c)$ and its first derivative $\mathrm{CMA}^{(1)}(c)$. A structural index being assumed, the location and depth of the source $a=a_{x}+\mathrm{i} a_{z}$ is directly obtained for each value of the coordinate $c$ without using a least-squares procedure in a window of given width.

Magnetic anomalies of different sources most often interact. A solution to reduce this issue is to increase the order of derivation (Cooper 2002, 2004; Hsu 2002; Florio et al. 2006; Fedi 2007). The generalization of eq. (5) is

$a=c+\frac{\mathrm{CMA}^{(p-1)}}{\mathrm{CMA}^{(p)}}(n+p-1)$,

with $p$ a real number corresponding to the order of derivation.

\section{RESULTS OF THE MAGNETIC ANALYSIS}

\subsection{Magnetic mapping of tunnel valleys}

As expected, the successive vertical derivative magnetic maps (Figs $3 \mathrm{c}-\mathrm{f}$ ) show that as the derivation order increases, the magnetic signature of the linear features amplifies, and the basement-induced long-wavelength magnetic anomalies attenuate. The vertical derivative map at 1.7 order $(a=b=0, c=1, n=1.7)$ has been retained (Fig. 3e) for further investigation since it corresponds to the best compromise enhancing details relative to the high-frequency magnetic lineations without amplifying too much the noise (compare to Fig. 3f). The correlation of the vertical derivative magnetic map of 1.7 order (Fig. 3f) to the TMI map (Fig. 3a) enables to distinguish the complex array of finely defined, curvilinear, cross-cutting magnetic lineations that we argue they essentially are the signature of tunnel valleys. Whether the latter are buried or not is at this stage unknown.

The horizontal gradient magnetic maps (Figs 4 and 5) reveal that the curvilinear magnetic anomalies are delineated by one, two 

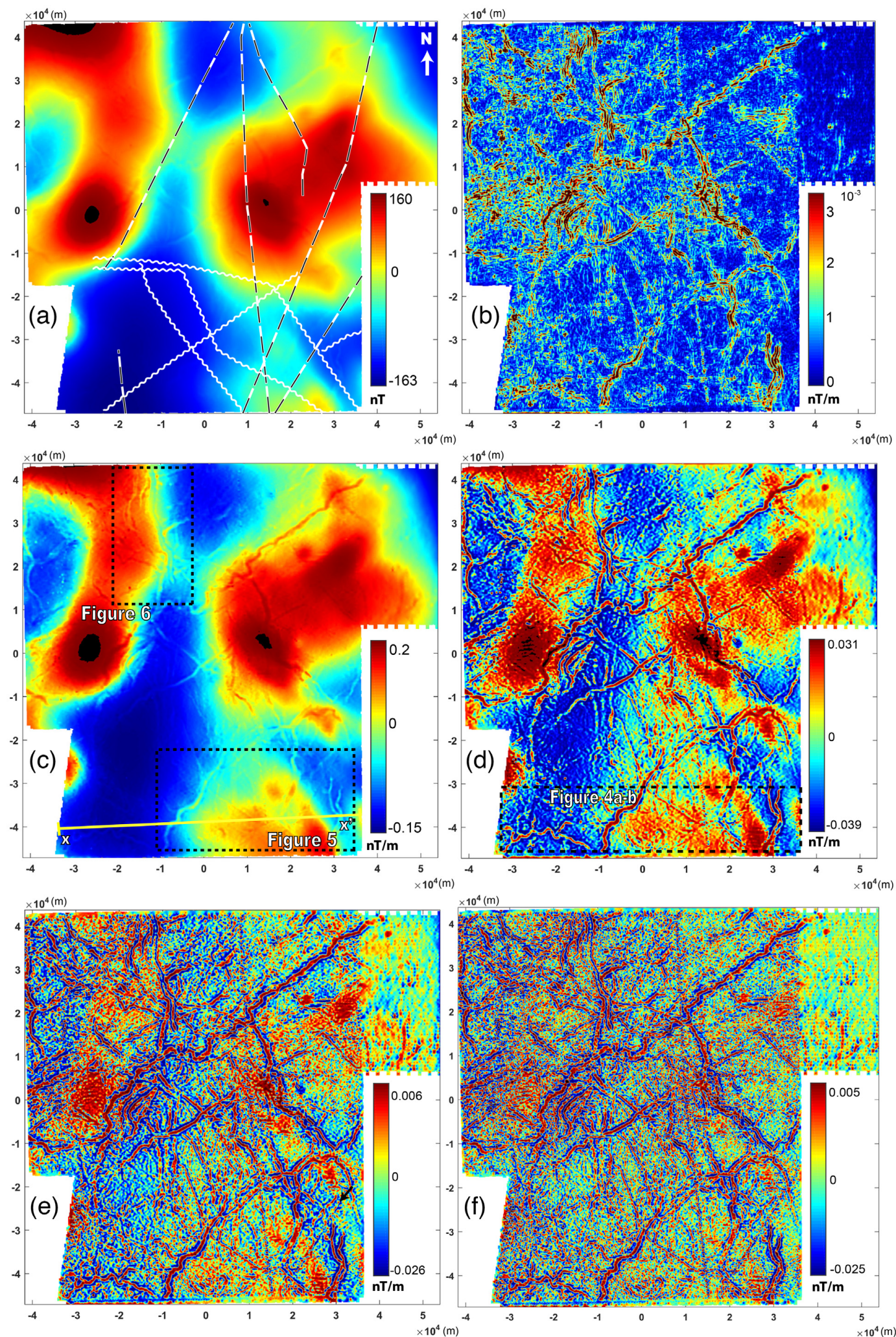

Figure 3. (a) Total Magnetic Intensity map; in white, gas and oil pipelines and submarine cables according to (FactMaps 2017, http://gis.npd.no/factmaps/ht ml_21/); (b) horizontal gradient map (linear colour scale bar) of 1.7 order applied on a reduced to the pole magnetic map; (c-f) vertical derivative (equal-area colour scale bar) magnetic maps of the orders of 0.5, 1.3, 1.7 and 2, respectively. Black arrows in (b), (e) and (f) show straight lineations, representative of non-geological structures; see panel (a). 

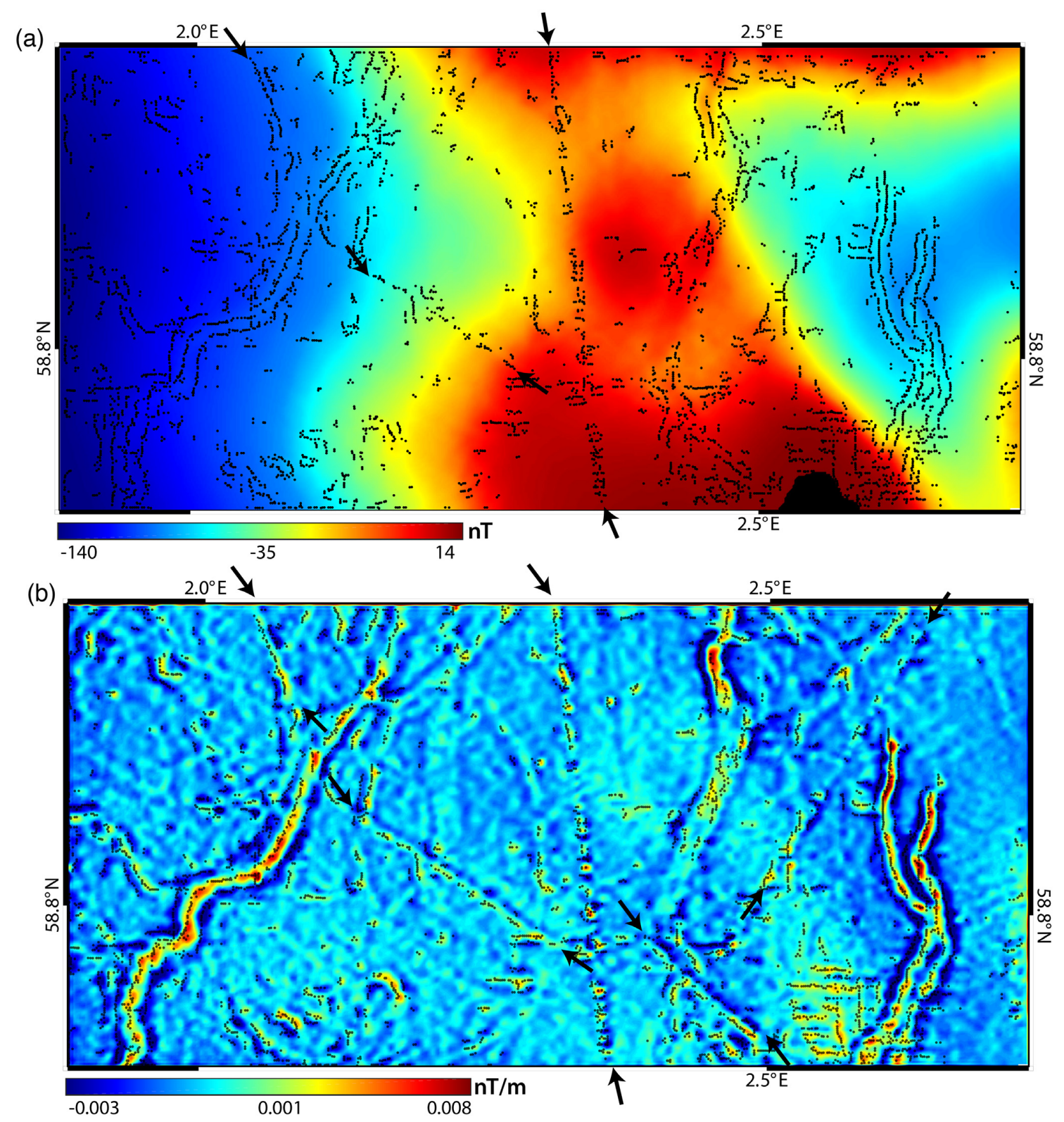

Figure 4. Plotted maxima of the horizontal gradient on (a) the TMI and on (b) the order 1.7 vertical derivative map (see Fig. 3a for location). Black arrows show straight lineations, representative of non-geological structures (gas and oil pipelines and submarine cables, see Fig. 3a).

or three, virtually parallel maximum anomaly lineations, which characterize the narrower, intermediate and wider valleys reported by Fichler et al. (2005), respectively. Regarding the wider valleys, it is noted that the minima of the vertical derivative coincide with the two lateral horizontal gradient maxima located from either side of the central maximum (Fig. 4). Note that the magnetic lineations displaying a straight and discontinuous line represent submarine cables or gas and oil pipelines (Figs 3 and 4, http://gis.npd.no/factmaps/html_21/).

\subsection{Magnetic and geometric properties of tunnel valleys}

\subsubsection{Extraction of high-frequency magnetic anomalies}

This study targets the high-frequency magnetic anomalies in order to characterize potential signatures of the channel structures. To proceed to the extraction of the high-frequency anomalies, we have modelled the long-wavelength anomalies on the basis of an E-W regional 2-D magnetic model (Maystrenko et al. 2017, their fig. 21) that shows the configuration of the crustal structure in the southern part of the study area (xx' in Fig. 3a).

In order to calculate the 2-D forward model, we used a same configuration of highly magnetized deep crustal layers and a top basement ranging from 2 to $10 \mathrm{~km}$ (Maystrenko et al. 2017). The calculated model reproduces first-order positive and negative parts of anomalies though it does not match closely the observed data, with a discrepancy amplitude anomaly up to $50 \mathrm{nT}$. This is due to the fact that the Maystrenko et al. (2017) framework, designed for large-scale crustal structures does not account for basement local heterogeneities. Therefore, we adjust the susceptibility values of the blocks and the top-basement depth (Fig. 2) in order to precisely match the observed data. The resulted curve of the difference between the observed and calculated anomalies shows residual 
(a)

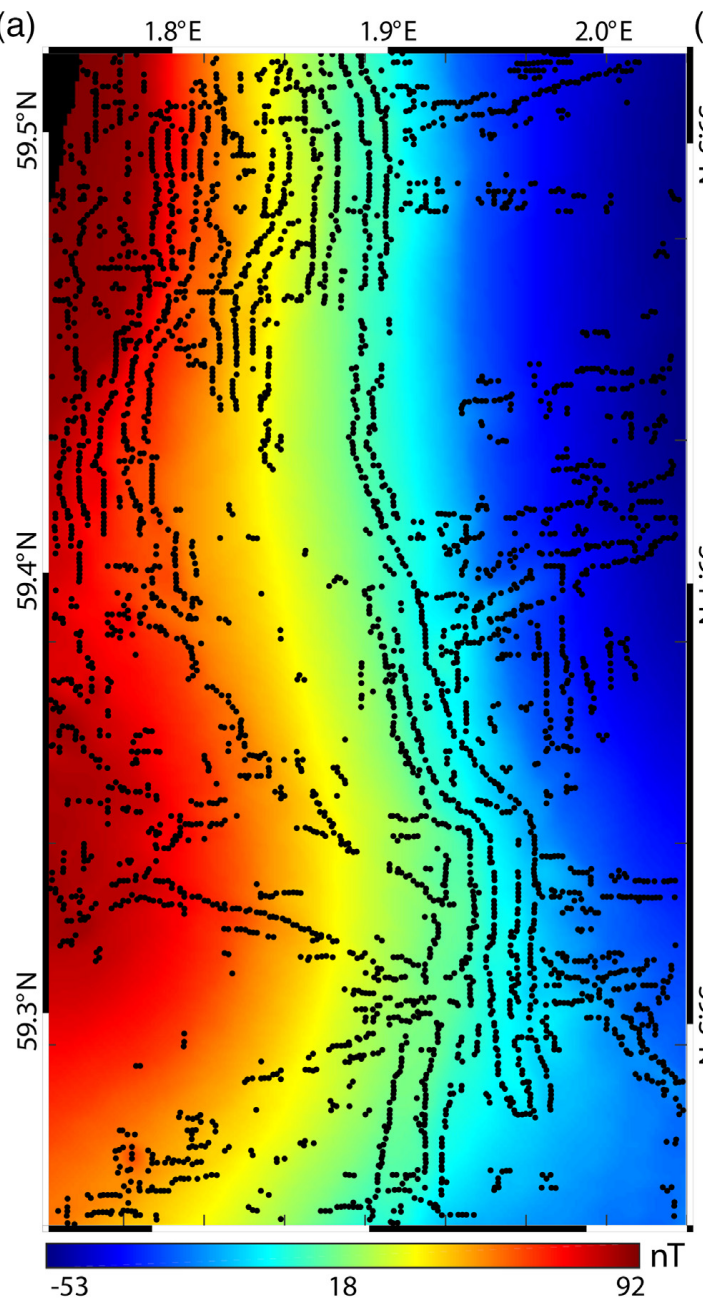

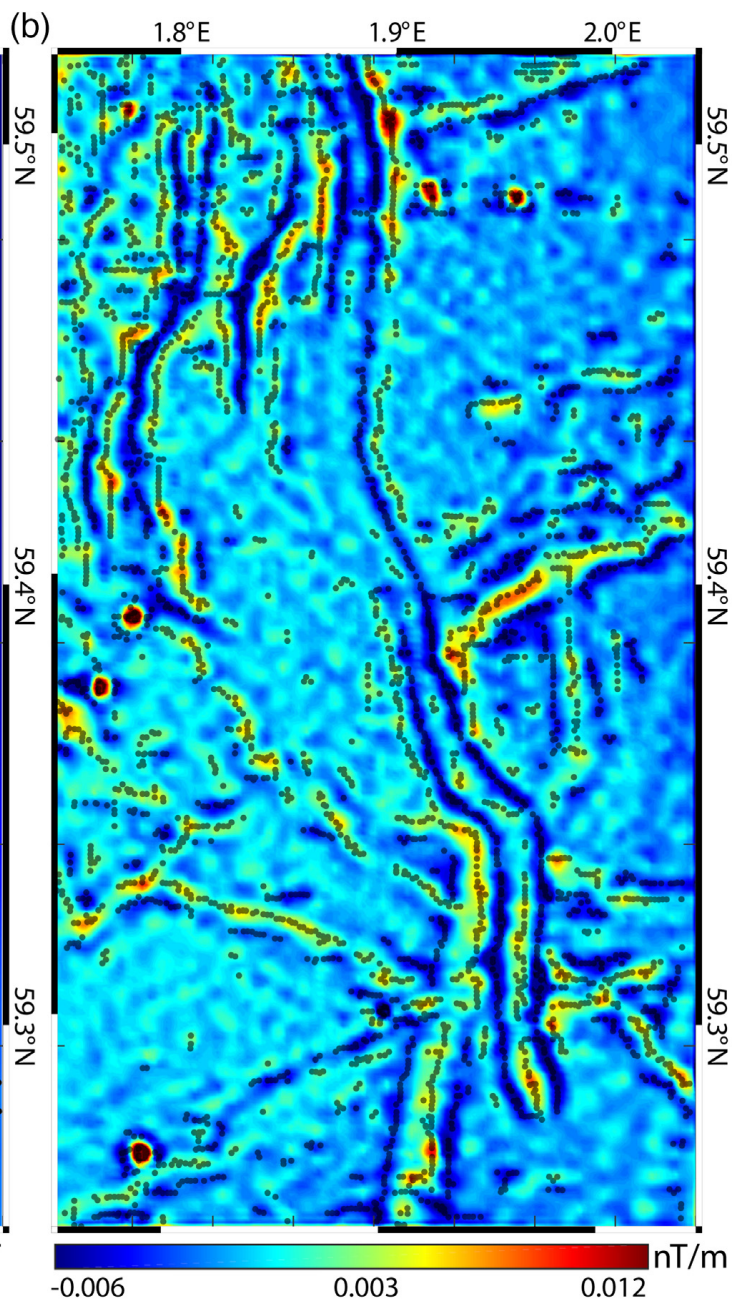

Figure 5. Plotted maxima of the order 1.7 horizontal gradient on the (a) TMI map and (b) order 1.7 vertical derivative map; see Fig. 3(a) for location.

high-frequency anomalies ranging between 1 and $10 \mathrm{nT}$ (Fig. 6d). As substantiated below, the magnetic maps (Fig. 6) evidence that these residual high-frequency anomalies correspond to sinuous lineations, which in the North Sea context are precisely interpreted as the signature of tunnel valley networks, as demonstrated by the direct comparison with the map of Fichler et al. (2005; their fig. 3a) based on a 3-D seismic survey.

\subsubsection{2-D forward modelling of tunnel valleys}

We perform 2-D forward modelling to investigate the magnetic source properties and geometries associated with sinuous magnetic anomalies by focusing on two examples for which the geometrical parameters of the channel structures are constrained either from seismic (a buried tunnel valley, figs 13a and b of Ottesen et al. 2014) or bathymetric data (Fig. 7, a non-filled or partly unfilled tunnel valley). First, we adjust at best the data using the simplest geometry, that is, a cylinder, for which unknowns are its horizontal location, depth and susceptibility. Secondly, the model sources use the output parameters derived from the simple geometrical model sources, with gradually more elaborated geometrical shapes accounting for geological constrains. Finally, in order to match the observed anomaly and using the susceptibility obtained at the first step, we formulate an inverse problem computing the shape of the magnetization layer, for which the modelled magnetic anomaly fit the data. This inverse problem is not linear, and convergence is reached by iteration using the simplex search method of Lagarias et al. (1998). The starting model of this inverse problem corresponds to a layer positioned at the depth of the simple model previously calculated and with a point horizontal spacing of $200 \mathrm{~m}$.

Model 1: buried tunnel valley Model 1 uses a profile extracted perpendicularly to a curvilinear magnetic anomaly (Fig. 7) displaying three extrema. It is generated by a buried tunnel valley as substantiated by 3-D seismic (Fichler et al. 2005, their fig. 6a; Ottesen et al. 2014, their figs 13a and b). For a start, we used a cylinder positioned at the depth of the valley thalweg as indicated by seismic data; the susceptibility being adjusted to match the data (Fig. 8a). The calculated anomaly is of too short-wavelength amplitude and does not reproduce the shape of the observed curve. The depth of the cylinder model source must be unrealistically deepened beyond $1000 \mathrm{~m}$, in order to partially match the shape of the observed anomaly curve, yet the minima of the anomaly is still not reproduced (Fig. 8b). Therefore, relatively shallow channel structures - at least regarding the North Sea tunnel valleys - cannot be reduced to a cylinder. A horizontal finite-width plate is in a second step introduced as a source geometry, the depth of which is positioned at the 
(a)

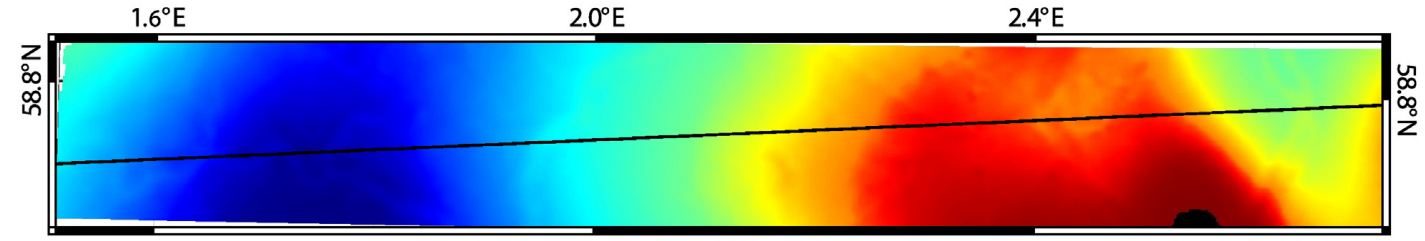

(b)

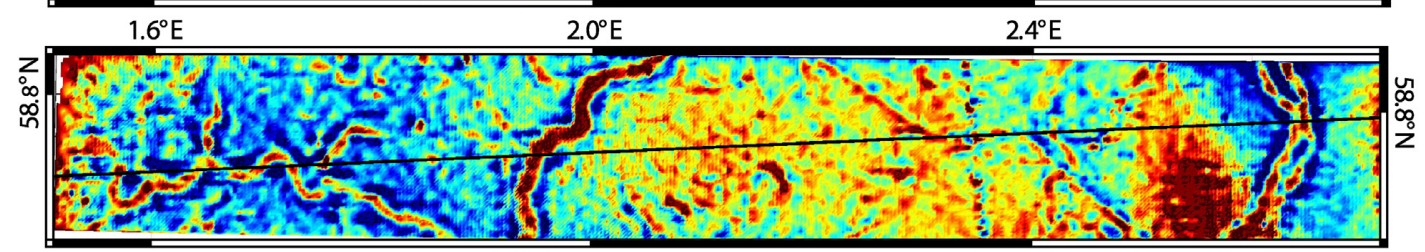

(c) -1
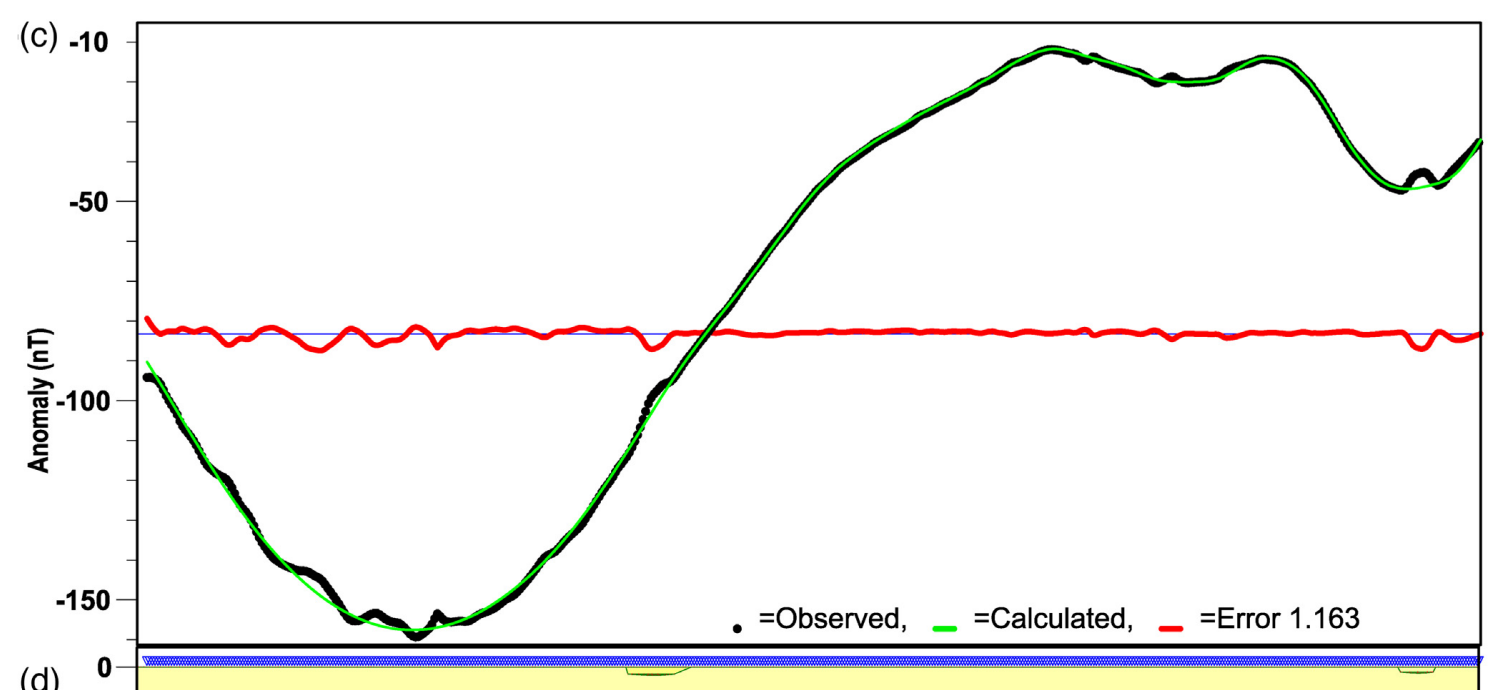

(d)
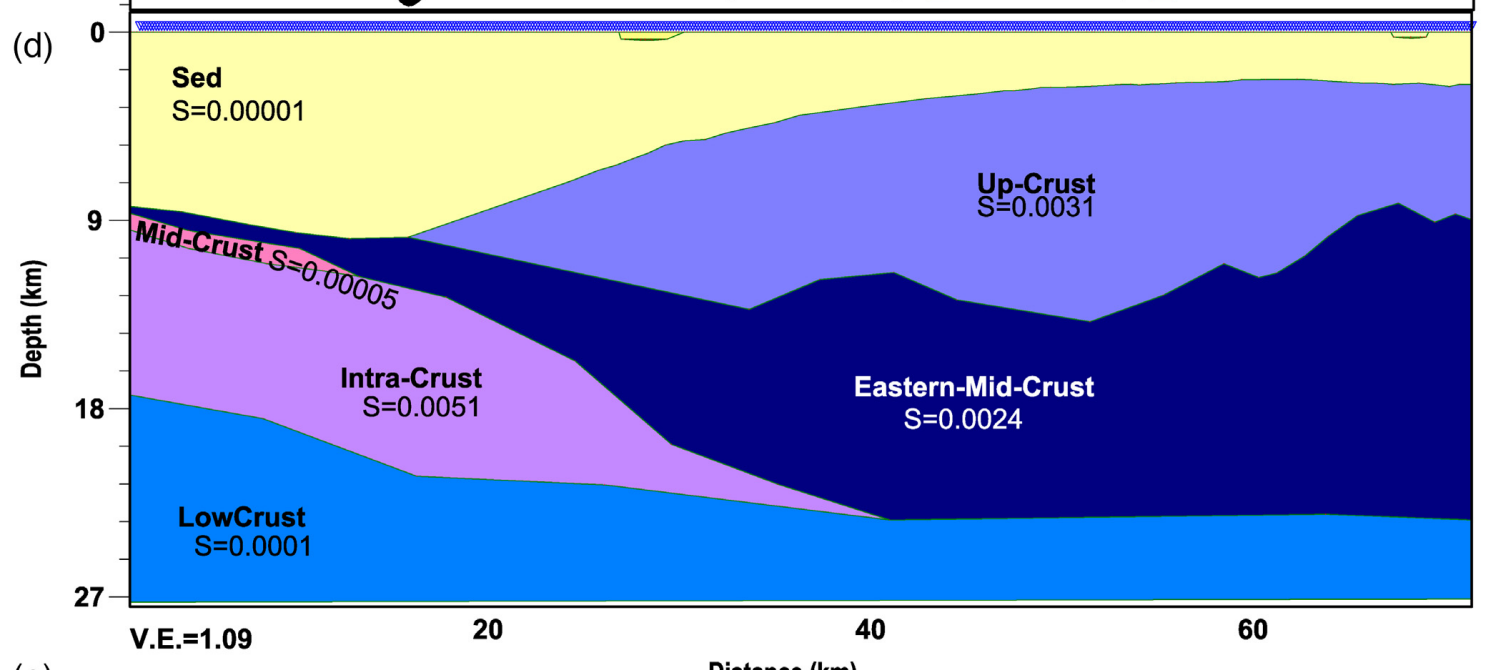

(e)

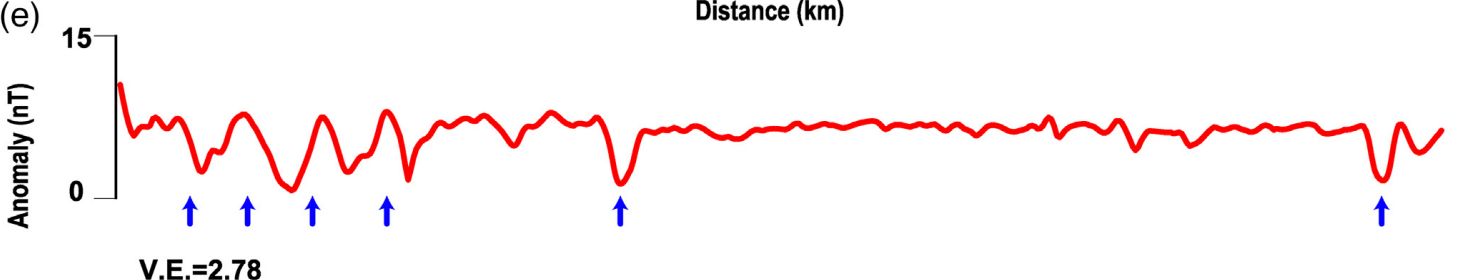

Figure 6. Magnetic 2-D forward modelling (profile $x-x$ ' in Fig. 3a). (a) TMI map; (b) order 1.7 vertical derivative magnetic map; (c) calculated and observed anomalies; (d) crustal-scale magnetic model; (e) vertical exaggeration applied to the residual anomaly curve obtained in (c), showing high-frequency anomalies ascribed to tunnel valley signatures (Fichler et al. 2005); V.E.: vertical exaggeration.

top of the seismic valley fill. We adjust the width and the susceptibility of the structure to match the data. It is interesting to note that most of the data are well reproduced by this very simple model source, which definitely is to be considered more appropriate than the cylinder model source. Nevertheless, we note a residual discrepancy between the modelled and observed maximum anomalies (green arrow, Fig. 8c). To minimize this discrepancy, the anomaly has to be modelled using a rectangular-shape source (Fig. 8d) 

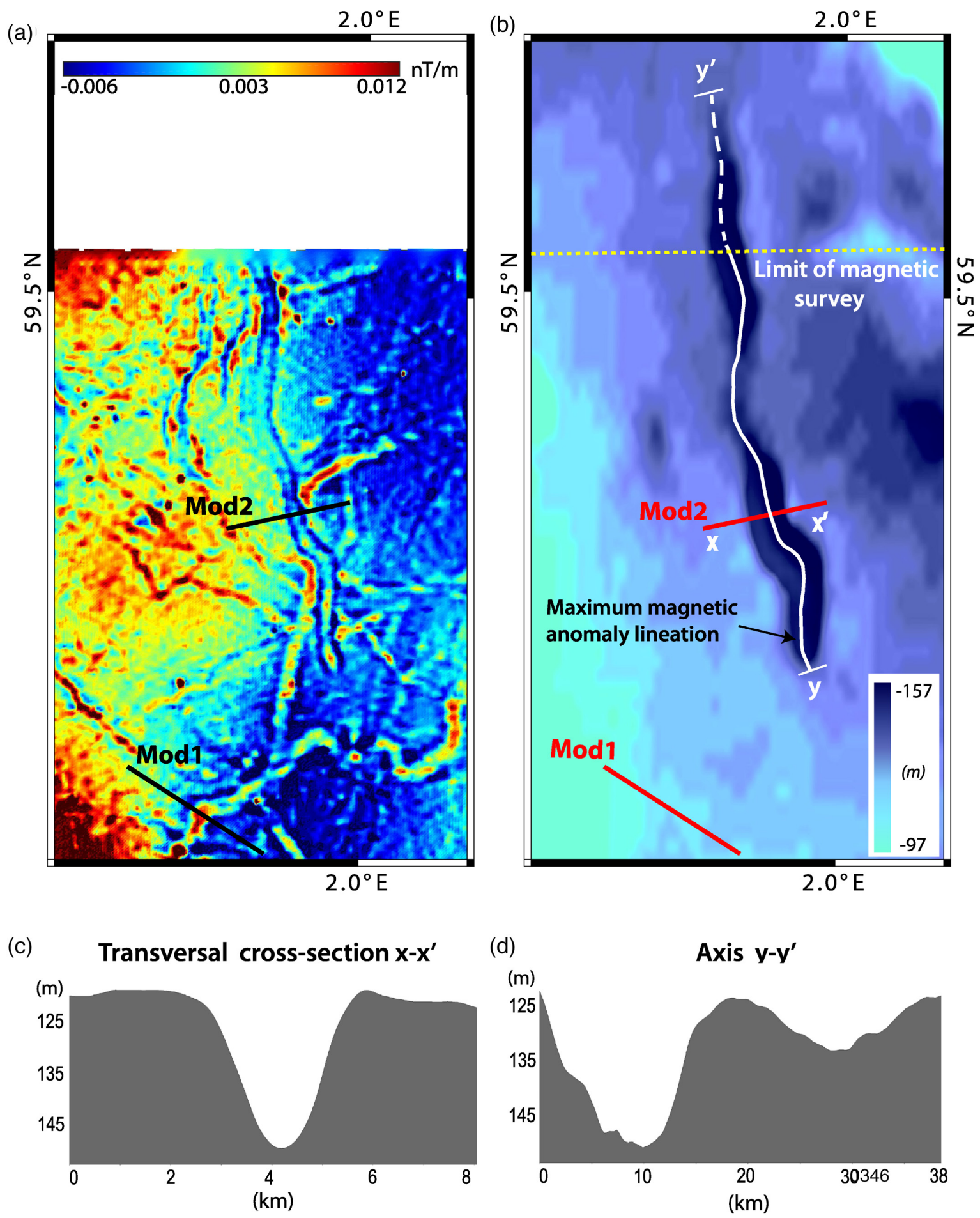

Figure 7. 2-D forward model profiles calculated for tunnel valleys. (a) Vertical derivative magnetic map of the order of 1.7; (b) bathymetry map (Weatherall et al. 2015) showing locations of 2-D magnetic models, corresponding to a buried tunnel valley with no bathymetric expression (Mod1, Fig. 8) and an underfilled tunnel valley (Mod2, Fig. 9). Cross-sections (c) and (d) show bathymetric profiles perpendicular ( $x-x^{\prime}$ ) and parallel (y-y') to the valley axis, respectively.

incorporating the proper valley thickness (determined by the seismic data). At this stage of the forward modelling the susceptibility of the model source is adequately constrained ( $0.0035 \mathrm{SI})$. If using a trapezoidal geometry instead of a rectangle, the maxima of the calculated anomaly have a better fit, showing that adjusting closely the magnetic anomalies have to potential to satisfactorily approximate the shape of a channel structure (Fig. 8e). Our last step consists in applying the data inversion as described above to obtain a more detailed outline for the magnetized layer. It is interesting to note that the outline finally obtained for the tunnel valley correlates well with the seismic cross-section (the yellow curve in Fig. 8f).

Vertical and horizontal derivatives anomalies are calculated for the model 1 (Fig. 8e) at the order of 1.7, and we observed an accurate match between the width of the trapezoid model and the 

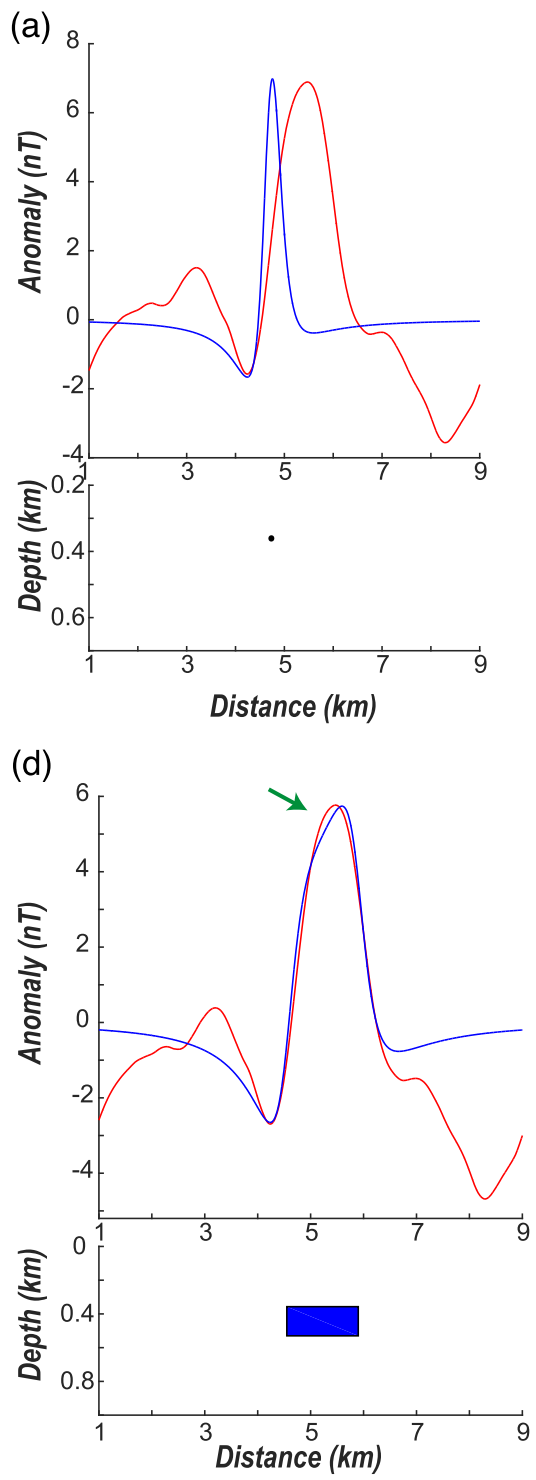

(b)

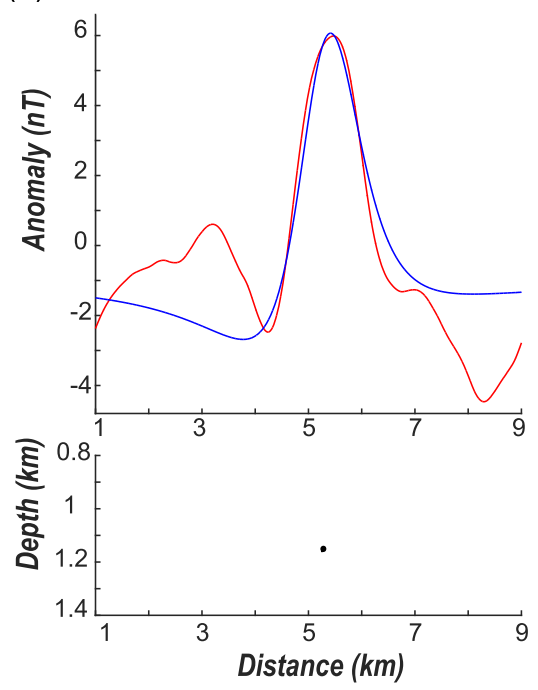

(e)

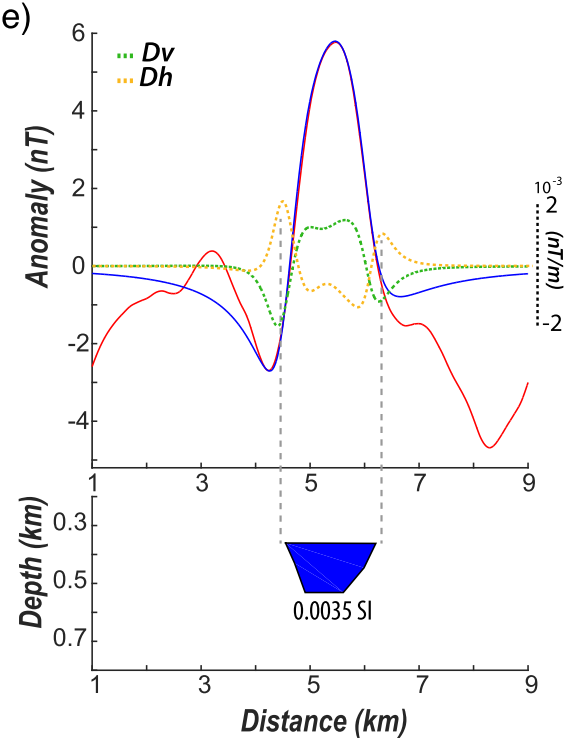

(c)

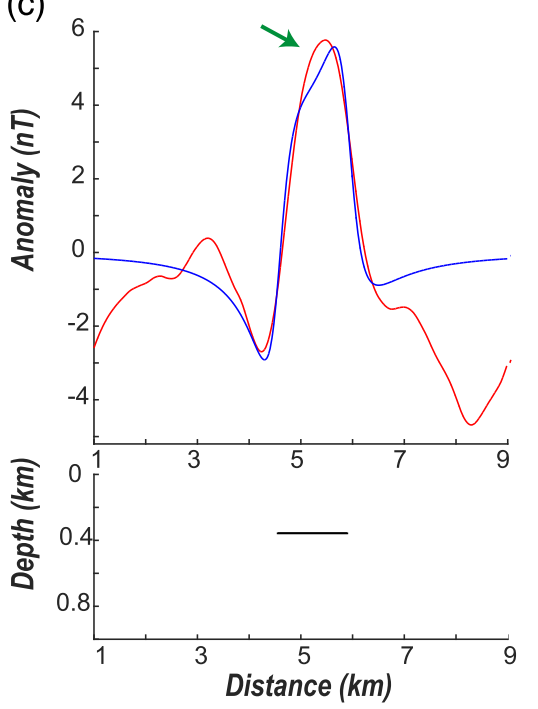

(f)

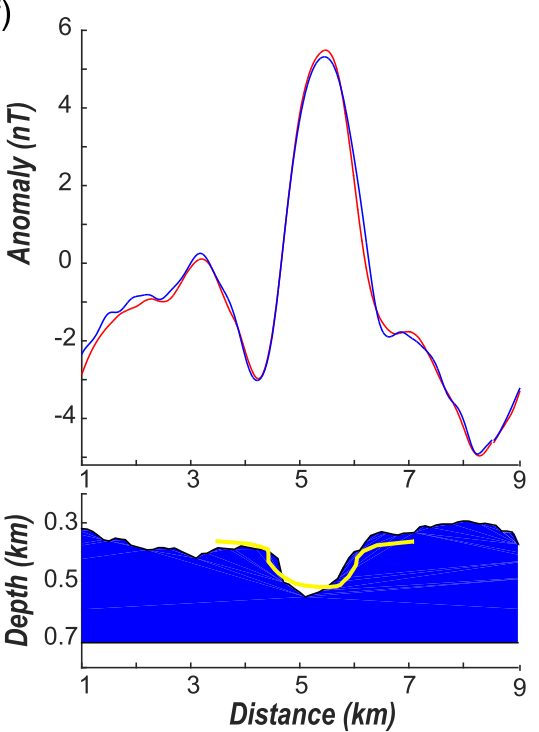

Figure 8. Results of magnetic 2-D forward modelling applied to a buried tunnel valley by using: (a) shallow cylinder; (b) deep cylinder; (c) horizontal finite-width plate; (d) rectangular shape positioned in depth relative to seismic data (data: red curve; model: blue curve; green arrows in panels (c) and (d) point to the discrepancy of the observed and calculated anomalies); (e) more realistic trapezoid shape. From the latter, a 0.0035 SI susceptibility value is determined; additional green and orange dashed curves represent order 1.7 vertical (Dv) and horizontal (Dh) derivatives, calculated using the synthetic magnetic anomaly; the two dashed vertical lines down to the valley profile emphasize the spatial correspondence of the limits of the model source and the minima of the vertical derivative and the maxima of the horizontal derivative. (f) Iterative depth inversion and comparison with the incision profile drawn from seismic data (Ottesen et al. 2014); here, shown in yellow.

distance between the two minima of the vertical derivative anomaly (orange dashed curve) and the two maxima of the horizontal gradient anomaly (green dashed curve). This allows us to generalize the width of all the tunnel valleys on the basis of magnetic anomaly lineations when using an automatic plot of the horizontal gradient.

Model 2: underfilled tunnel valley Model 2 is performed on the basis of a bathymetric profile data characterizing a tunnel valley that was left underfilled after deglaciation (Figs $7 \mathrm{~b}$ and c). As for model 1 , the first step consists to estimate the parameters of the magnetic sources by using a cylinder model source (Figs 9a and b). As well, the data cannot be reproduced with a simple cylinder. The second step uses a horizontal-finite width plate as model source (Fig. 9c), positioned at the residual valley depth. Note that the data are relatively well reproduced, by adjusting the width and susceptibility of the horizontal-finite width plate. However, the small central peak of the calculated anomaly does not match precisely the data. Compared to the model 1 a negative susceptibility is used because the tunnel valley is mainly filled with water. It would be more appropriate to model the magnetic anomaly with a rectangular incision (Fig. 9d), using the width already determined by the horizontal finite-width plate and incorporating the residual incision depth shown on bathymetric data (Fig. 7c).

Finally, the reverse iterative method is applied (Fig. 9e). It is interesting to note that the maxima and minima of the observed anomaly match well when adjusting the slopes of the incision (Fig. 8e). However, the geometry of the resulting incision again includes a 
(a)

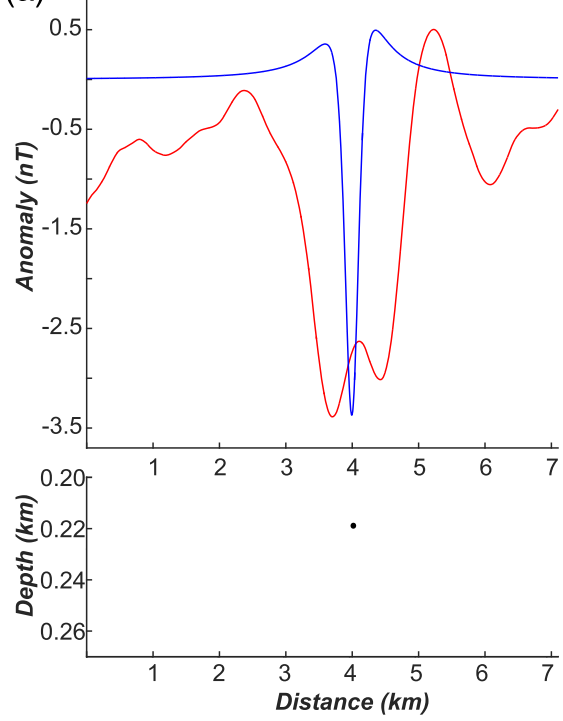

(d)

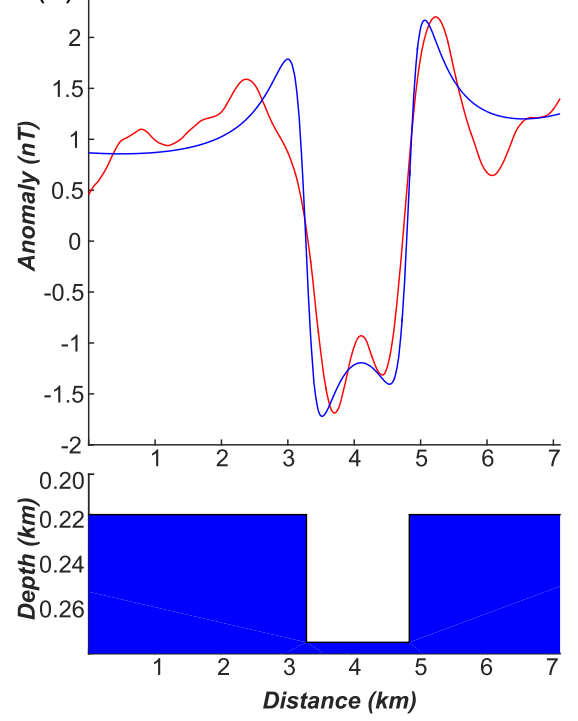

(b)

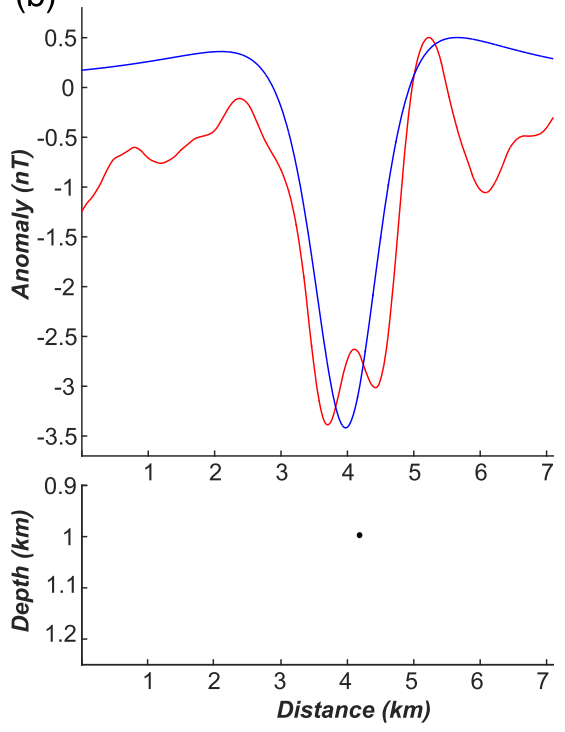

(e)

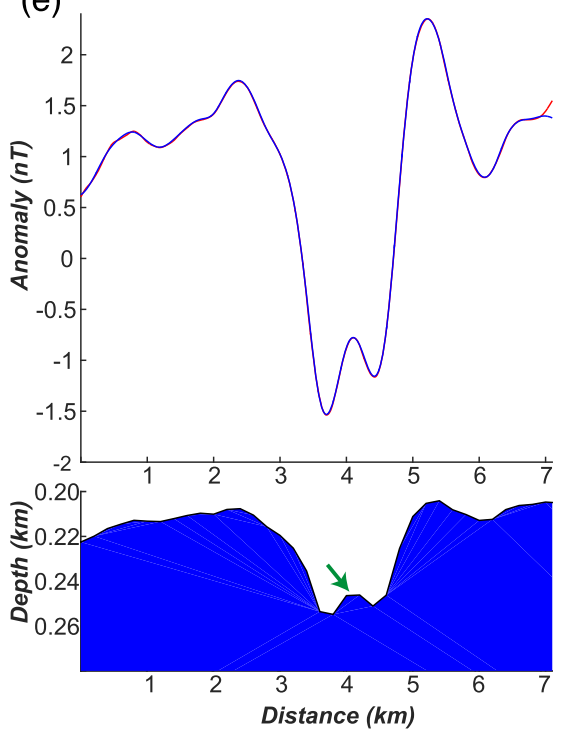

(c)

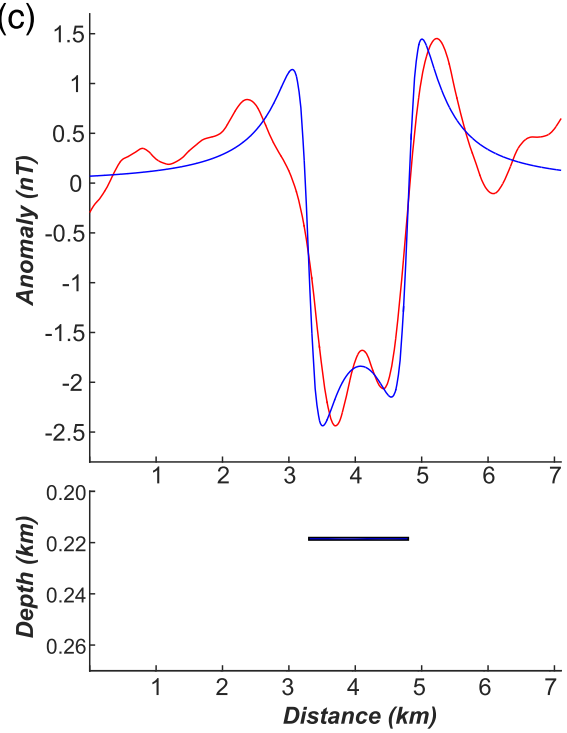

(f)

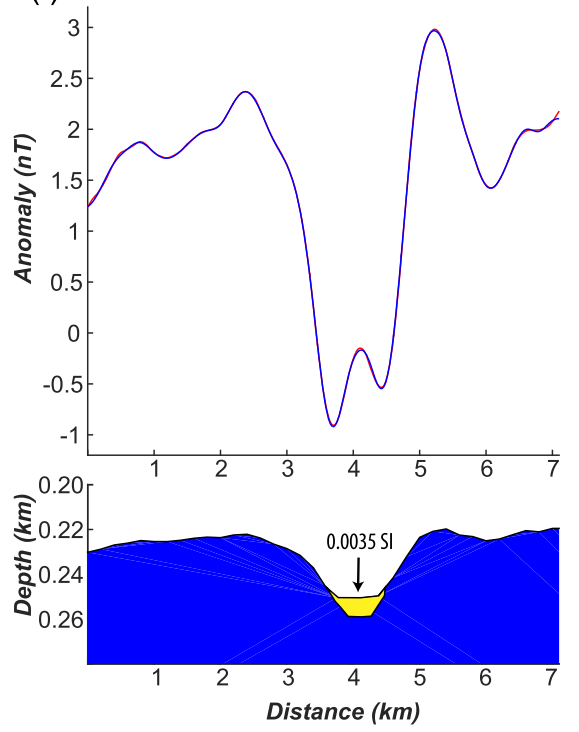

Figure 9. Results of magnetic 2-D forward modelling applied to an unfilled valley using (data: red curve, model: blue curve): (a) shallow cylinder; (b) deep cylinder; (c) horizontal finite-width plate; (d) rectangular shape; (e) iterative inversion; green arrow shows positive relief at the incision bottom, not corresponding to a bathymetric feature (Fig. 7c); (f) iterative inversion of data minus the magnetic effect of the polygon under the bathymetric incision (yellow polygon).

positive relief at the bottom of its basal surface (Fig. 9e), which does not conform to the bathymetric cross-section (Fig. 7c). As a consequence, we added a magnetized polygon reflecting a partial valley infill that is more magnetized than its surrounding (the yellow polygon in Fig. 9f). This tunnel valley is thus demonstrated to be largely underfilled and not empty of sediment.

\subsubsection{Euler deconvolution and CMA}

Fig. 10 shows for 844 magnetic profiles at right angle to the tunnel valleys, the location and the depth computation using Euler deconvolution in the complex domain (see Section 4). These results were obtained for four different scenarios: (1) $n=1, p=1$; (2) $n=1$, $p=1.7$; (3) $n=1.5, p=1$; (4) $n=1.5, p=1$.7. In complex algebra, the structural index of a cylinder is equal to 2 and for a semi-infinite plane is equal to 1 . That is why we choose values 1 and 1.5 and not 2 because the cylindrical characteristic of the geometry was eliminated in the forward modelling. In each case, we compute $a\left(=a_{x}+i a_{z}\right)$ for each value of the coordinate near the axis of tunnel valley ( $1.7 \mathrm{~km}$ on both sides). The results, displayed on Fig. 10, correspond to the mean value of $a_{x}$ for the location along the profile and to the mean depth $\left(a_{z}\right)$ for a colour chart.

The depth colour chart is the same for all of the four maps, ranging from 200 to $600 \mathrm{~m}$. We observe in the maps with $p=1$ (Figs 10a and $b$ ) that the depth values are deeper in areas where long wavelength anomalies are present (areas outlined in red, Figs 10a and c). To minimize the interaction with long wavelength anomalies, the depth calculation is done with a 1.7 order derivative (Figs 10c and d). The depths obtained are shallower: $313 \mathrm{~m}(n=1, p=1.7)$ and $379 \mathrm{~m}(n=1.5, p=1.7)$, with respect to the forward models 1 and 


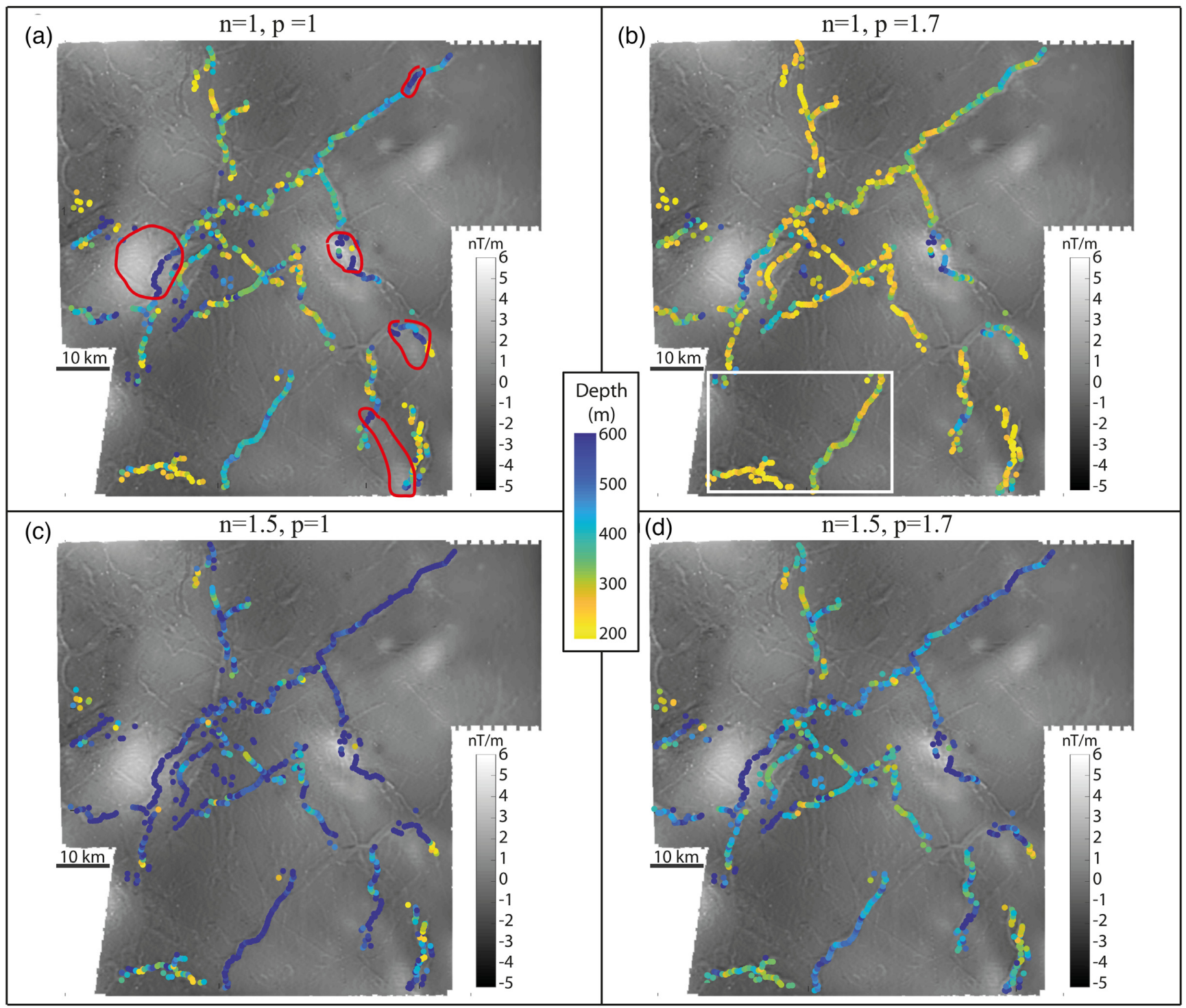

Figure 10. Results of the depth estimation on the basis of the Euler deconvolution using complex algebra superimposed on the 1.7 order vertical derivative; depth range is $200-600 \mathrm{~m}$ (100 m flight altitude is included within these values); $n$, structural index; $p$, derivative order; Euler' solution are calculated with: (a) $n=1$ and $p=1$; (b) $n=1$ and $p=1.7$; (c) $n=1.5$ and $p=1$; (d) $n=1.5$ and $p=1.7$; red lines localize long wavelength anomalies with higher depths.

Table 1. Estimated depth using Euler deconvolution in the complex domain, applied to the model tunnel valleys 1 and 2 .

\begin{tabular}{|c|c|c|c|c|}
\hline \multirow{2}{*}{$\begin{array}{l}\text { Derivative order } \\
\text { Structural index }\end{array}$} & \multicolumn{2}{|c|}{$p=1$} & \multicolumn{2}{|c|}{$p=1.7$} \\
\hline & $n=1$ & $n=1.5$ & $n=1$ & $n=1.5$ \\
\hline $\begin{array}{l}\text { Forward model } 1 \\
\text { (Fig. 8f) }\end{array}$ & $379 \mathrm{~m}$ & $569 \mathrm{~m}$ & $309 \mathrm{~m}$ & $464 \mathrm{~m}$ \\
\hline $\begin{array}{l}\text { Forward model } 2 \\
\text { (Fig. 9f) }\end{array}$ & $303 \mathrm{~m}$ & $454 \mathrm{~m}$ & $151 \mathrm{~m}$ & $226 \mathrm{~m}$ \\
\hline
\end{tabular}

2. The best depths are obtained for $n=1.5$ and $p=1.7$ (Table 1, orange cells). Fig. 10(b) (white rectangle) shows two sets of valley depths, suggesting the east-west oriented valley is shallower than the north-south oriented valley. This semi-automatic estimates for tunnel valley depths are well compared to the 3-D reconstruction of Fichler et al. (2005). It corroborates the initial assumption that a structural index of 1.5, as initially suggested by our 2-D forward modelling, can be used for the Euler deconvolution method of magnetic anomalies linked to channel structures.

\section{DISCUSSION AND CONCLUSION}

The results obtained for the magnetic characterization of channel structures on the basis of a North Sea tunnel valley networks are promising, especially if combining successively the outputs of the different methods (fractional derivation, forward modelling, Euler's deconvolution).

In map view, the spatial organization of the tunnel valley networks has been deciphered using the fractional vertical derivative and horizontal gradient transforms (Figs 3-5). We have shown that those derived at order of 1.7 offer the best compromise (Fig. 3). By plotting automatically the extrema (Fig. 11), the network of superimposed tunnel valleys of different generation is accurately mapped. Three categories of magnetic anomaly lineations associated to the valleys are identified (Figs 3 and 11b): (i) high-frequency and highamplitude curvilinear magnetic anomalies dominated by a major central peak anomaly (red lineations in Fig. 11b), which is the case of most of the valley infills; (ii) high-frequency and high-amplitude curvilinear magnetic anomalies dominated by a subordinate central peak anomaly (green lineations in Fig. 11b), which correspond 

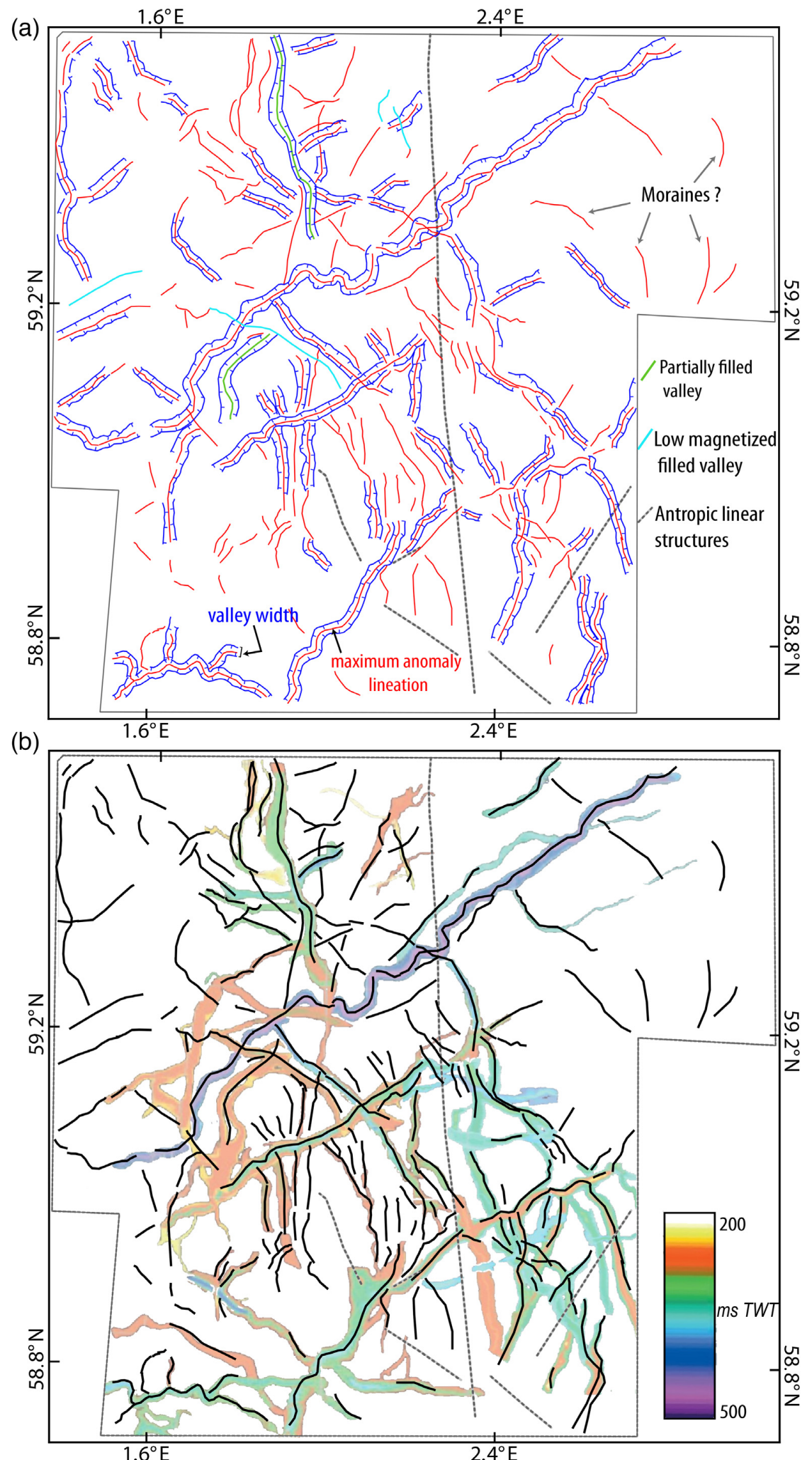

Figure 11. Correlation magnetic and seismic tunnel valley analysis. (a) Generalized tunnel valley widths; (b) map showing the correlation of the seismic tunnel valley and the magnetic anomaly lineations' extent; black lines correspond to the maxima of vertical derivative magnetic anomalies. 
to underfilled tunnel valleys (see model 2; Figs 5 and 7a-b; green lineations in Fig. 11a); (iii) high-frequencies, low-amplitude magnetic anomalies with a central minima (cyan lineations in Fig. 11b), which characterize a few tunnel valley fills for which magnetization is weaker than in the host sediments.

From 2-D forward modelling it has been shown that the width of the magnetic lineations, for instance the spacing of the two extrema bracketing a central peak when considering the vertical or horizontal derivatives (Fig. 8e, green and orange curves), fairly reflect the palaeovalley width modelled (Fig. 11), this estimate being independent of other known geological information. Therefore, we argue that the map of Fig. 11(a) confidently shows a network of tunnel valleys, which the individual valley widths have been entirely determined on the basis of the width of each magnetic lineation. This is checked for the valleys of the North Sea, close to the polar zone, where the magnetic anomalies are localized almost directly above the source bodies, this would not be applicable for channels located in low latitudes.

As the magnetization of the infill sediments is proportional to the incision thicknesses, going further with 2-D modelling necessitates additional information precising either the susceptibility value of the valley infill or its depth. However, this range will be limited, as it must explain the observed anomalies. For the calculated 2-D models, magnetic susceptibility is constrained by the use of known thicknesses of seismic (Ottesen et al. 2014, their fig. 13) and bathymetry (Fig. 7c), which would most likely correspond to a clayey nature of the infill sediments, according to the petrophysical interpretation of Britt \& Olesen (1996).

Nevertheless, our results also allowed us to define the structural index (1.5) of a channel structure that can be used in the Euler's deconvolution method, by which depth of the magnetic bodies can be computed without geological constrains. Applying the Euler deconvolution using complex algebra, an independent range of depth values is obtained. Though absolute depth values are to be understood only as first order estimate - the computed depth is suggested reflecting the 'average' depth of the valley fill - they highlight interesting longitudinal changes such as progressive deepening or irregular thalweg profiles (Fig. 11). In addition, such depth values can be used in positioning vertically the superimposition of channel structures, which may help to decipher successive generation of incisions, and infill where seismic data are absent or of low-resolution.

The comparison of the results obtained from the detailed analysis of magnetic data with the systematic mapping derived from seismic one (Fichler et al. 2005) reveals that most of the tunnel valleys are identified with our methods (Fig. 11a). Regarding the few valleys not detected, two cases can be envisioned, which may be combined: (i) the magnetization of the valley fill is close to the one of the surrounding sediments, generating too weak magnetic contrasts; (ii) the incision thickness and subsequent infill are reduced and magnetically undetectable. Conversely, some magnetic lineations have not been reported as tunnel valleys on the Fichler et al.'s map, though that they have a magnetic signature very close to those identified as tunnel valleys (see the northeastern area of the case study, Fig. 11a). They could correspond to minor incisions or correspond to other relatively small-scale structures such as morainal banks or segments of glaciotectonic belts.

In this study, we have shown that magnetic anomalies allow us to map network of channel structures. They have been proven to be very efficient the complex network of late Quaternary tunnel valleys in the North Sea and can be advantageously used for the mapping of large-scale area in the absence of a continuous 3-D seismic cover. Furthermore, a full set of estimates of physical and geometric parameters (wide, depth) can be obtained as soon as restricted constrains are available, which can be either the susceptibility of the infill (from drill data) or the width of the incision (from non-migrated 2-D seismic cross-profiles). The combined use of extensive magnetic data, which are relatively easy to acquire at low cost, with a limited set of 2-D seismic lines is promising, not only for systematic geographic mapping of channel networks but also for deciphering superimposed multigeneration networks using the Euler deconvolution. Other channel structures in other contexts, such as fluvial channels or buried palaeovalleys should be efficiently detected, mapped and geometrically characterized by using aeromagnetic methods. Another challenge is now to use aeromagnetic anomalies to detect at depth in sedimentary basin older channel structures buried under hundreds or thousands of meter of sediment, such as North African or Arabian Palaeozoic tunnel valleys, which constitute significant groundwater or hydrocarbon reservoirs (Douillet et al. 2012; Van der Vegt et al. 2012) that can be theoretically detected on aeromagnetic anomaly maps provided high resolution data set are available.

\section{ACKNOWLEDGEMENTS}

The authors wish to thank TGS-NOPEC Geophysical Company for providing access to the aeromagnetic data. The authors are thankful to Christine Fichler and an anonymous reviewer, whose comments greatly contributed to the improvement of the original manuscript.

\section{REFERENCES}

Amante, C. \& Eakins, B.W., 2009. ETOPO1 arc-minute global relief model: procedures, data sources and analysis. NOAA Technical Memorandum NESDIS NGDC-24. National Geophysical Center, NOAA. doi:10.7289/V5C8276M.

Amarok, A.S., 1994. Processing report of TGS-Nopec on VGVG-94, Aeromagnetic Bloc 25, Norwegian Central North Sea.

Andreassen, K., Nilssen, E.G. \& Ødegaard, C.M., 2007. Analysis of shallow gas and fluid migration within the Plio-Pleistocene sedimentary succession of the SW Barents Sea continental margin using 3D seismic data, Geo Mar. Lett., 27, 155-171.

Anell, I., Thybo, H. \& Rasmussen, E., 2011. A synthesis of Cenozoic sedimentation in the North Sea, Basin Res., 23, 1-26

Auken, E., Jørgensen, F. \& Sørensen, K.I., 2003. Large-scale TEM investigation for ground-water, Explor. Geophys., 33, 188-194

Babaahmadi, A. \& Rosenbaum, G., 2015. Kinematics of orocline-parallel faults in the Texas and Coffs Harbour oroclines (eastern Australia) and the role of flexural slip during oroclinal bending, Aust. J. Earth Sci., 62, 933-948.

Baranov, V., 1957. A new method for interpretation of aeromagnetic maps: pseudo-gravimetric anomalies, Geophysics, 22, 359-382.

Bauer, C. \& Fichler, C., 2002. Quaternary lithology and shallow gas from high resolution gravity and seismic data in the central North Sea, Pet. Geosci., 8, 229-236.

Benvenuti, A. \& Moscariello, A., 2016. High-resolution seismic geomorphology and stratigraphy of a tunnel valley confined ice-margin fan (Elsterian glaciation, Southern North Sea), Interpretation, 4, T461-T483.

Blakely, R.J. \& Simpson, R.W., 1986. Approximating edges of source bodies from magnetic or gravity anomalies, Geophysics, 51, 1494-1498.

Bournas, N., Galdeano, A., Hamoudi, M. \& Baker, H., 2003. Interpretation of the aeromagnetic map of Eastern Hoggar (Algeria) using the Euler deconvolution, analytic signal and local wavenumber methods, J. Afr. Earth Sci., 37, 191-205. 
Brahimi, S., Liégeois, J.-P., Ghienne, J.-F., Munschy, M. \& Bourmatte, A., 2018. The Tuareg shield terranes revisited and extended towards the northern Gondwana margin: magnetic and gravimetric constraints, Earth Sci. Rev., 185, 572-599.

Britt, M. \& Olesen, O., 1996. Magnetic susceptibility of sedimentary rocks from shallow cores off mid Norway and crystalline rocks from adjacent on land areas NAS-94 interpretation report IIB: petrophysical data revised version, Report 96.013.

BurVal Working Group, 2006. Groundwater Resources in Buried Valleys-a Challenge for Geosciences, Leibniz Institute for Applied Geosciences.

Cooper, G. \& Cowan, D., 2003. The application of fractional calculus to potential field data, Explor. Geophys., 34(2), 51-56.

Cooper, G.R.J., 2002. Fixed point inversion of geophysical data, Comput. Geosci., 28, 799-808.

Cooper, G.R.J., 2004. The semi-automatic interpretation of geophysical data, Explor: Geophys., 35(3), 180-185.

D’Errico, J., 2010. Surface Fitting Using Gridfit, Matlab Central, Mathworks. Inc.

Douillet, G., Ghienne, J.-F., Géraud, Y., Abueladas, A., Diraison, M. \& AlZoubi, A., 2012. Late Ordovician tunnel valleys in southern Jordan, Geol. Soc., London, Spec. Publ., 368, 275-292.

Ehlers, J., 1996. Quaternary and Glacial Geology, John Wiley and Sons Ltd., 578 pp.

Evans, D., 2003. The Millennium Atlas: Petroleum Geology of the Central and Northern North Sea; [a Project of the Geological Society of London, the Geological Survey of Denmark and Greenland and the Norwegian Petroleum Society ].

FactMaps, NPD 2017. Norwegian Petroleum directorate. http://gis.npd.no./ factmaps/html_21/

Faleide, J.I., Kyrkjebo, R., Kjennerud, T., Gabrielsen, R.H., Jordt, H., Fanavoll, S. \& Bjerke, M.D., 2002. Tectonic impact on sedimentary processes during Cenozoic evolution of the northern North Sea and surrounding areas, Geol. Soc., London, Spec. Publ., 196, 235-270.

Fedi, M., 2007. DEXP: a fast method to determine the depth and the structural index of potential fields sources, Geophysics, 72, I1-I11.

Fichler, C., Henriksen, S., Rueslaatten, H. \& Hovland, M., 2005. North Sea Quaternary morphology from seismic and magnetic data: indications for gas hydrates during glaciation?, Pet. Geosci., 11, 331-337.

Florio, G., Fedi, M. \& Pasteka, R., 2006. On the application of Euler deconvolution to the analytic signal, Geophysics, 71, L87-L93.

Gabriel, G., 2006. Gravity investigation of buried Pleistocene subglacial valleys, Near Surf. Geophys., 4(5), 321-332.

Gabriel, G., Kirsch, R., Siemon, B. \& Wiederhold, H., 2003. Geophysical investigation of buried Pleistocene subglacial valleys in Northern Germany, J. Appl. Geophys., 53, 159-180.

Galloway, W.E., 2002. Paleogeographic setting and depositional architecture of a sand-dominated shelf depositional system, Miocene Utsira Formation, North Sea Basin, J. Sediment. Res., 72, 476-490.

Gavazzi, B., Alkhatib-Alkontar, R., Munschy, M., Colin, F. \& Duvette, C., 2017. On the use of Fluxgate 3-Axis magnetometers in archaeology: application with a multi-sensor device on the site of Qasr "Allam in the Western Desert of Egypt, Archaeol. Prospect., 24, 59-73.

Gibbard, P.L. \& Lewin, J., 2016. Filling the North Sea Basin: Cenozoic sediment sources and river styles (André Dumont medallist lecture 2014), Geol. Belgica, 19, 201-217.

Gowers, M.B., Holtar, E. \& Swensson, E., 1993. The structure of the Norwegian Central Trough (Central Graben area), Geol. Soc., London, Pet. Geol. Conf. Ser., 4, 1245-1254.

Grauch, V. \& Cordell, L., 1987. Limitations of determining density or magnetic boundaries from the horizontal gradient of gravity or pseudogravity data, Geophysics, 52, 118-121.

Hsu, S.-K., 2002. Imaging magnetic sources using Euler's equation, Geophys. Prospect., 50(1), 15-25.

Huuse, M. \& Lykke-Andersen, H., 2000. Over deepened Quaternary valleys in the eastern Danish North Sea: morphology and origin, Quat. Sci. Rev., 19, 1233-1253

Huuse, M., Lykke-Andersen, H. \& Michelsen, O., 2001. Cenozoic evolution of the eastern Danish North Sea, Mar. Geol., 177, 232-269.
Huuse, M., Lykke-Andersen, H. \& Piotrowski, J.A., 2003. Geophysical investigations of buried Quaternary valleys in the formerly glaciated NW European lowland: significance for groundwater exploration, J. Appl. Geophys., 53, 153-157.

Høyer, A.-S., Jørgensen, F., Sandersen, P.B.E., Viezzoli, A. \& Møller, I., 2015. 3D geological modelling of a complex buried-valley network delineated from borehole and AEM data, J. Appl. Geophys., 122, 94-102.

Isaksen, G. H., Patience, R., van Graas, G. \& Jenssen, A.I., 2002. Hydrocarbon system analysis in a rift basin with mixed marine and nonmarine source rocks: the South Viking Graben, North Sea, AAPG Bull., 86, 557591.

Jarsve, E.M., Faleide, J.I., Gabrielsen, R.H. \& Nystuen, J.P., 2014. Mesozoic and Cenozoic basin configurations in the North Sea, in From Depositional Systems to Sedimentary Successions on the Norwegian Continental Margin, pp. 417-452, eds Martinius, A.W., Ravnås, R., Howell, J.A., Steel, R.J. \& Wonham, J.P., John Wiley and Sons, Ltd.

Jessell, M., Boamah, K., Duodu, J.A. \& Ley-Cooper, Y., 2015. Geophysical evidence for a major palaeochannel within the Obosum Group of the Volta Basin, Northern Region, Ghana, J. Afr. Earth Sci., 112, $586-596$.

Jørgensen, F. \& Sandersen, P.B.E., 2006. Buried and open tunnel valleys in Denmark - erosion beneath multiple ice sheets, Quat. Sci. Rev., 25, 1339-1363.

Jørgensen, F., Sandersen, P.B.E. \& Auken, E., 2003. Imaging buried Quaternary valleys using the transient electromagnetic method, J. Appl. Geophys., 53, 199-213.

Kehew, A.E., Piotrowski, J.A. \& Jørgensen, F., 2012. Tunnel valleys: concepts and controversies - a review, Earth Sci. Rev., 113, 33-58.

Kirsch, R.(Ed.), 2006. Groundwater Geophysics: A Tool for Hydrogeology, Springer.

Kluiving, S.J., Aleid Bosch, J., Ebbing, J.H., Mesdag, C.S. \& Westerhoff, R.S., 2003. Onshore and offshore seismic and lithostratigraphic analysis of a deeply incised Quaternary buried valley system in the Northern Netherlands, J. Appl. Geophys., 53, 249-271.

Kristensen, T.B. \& Huuse, M., 2012. Multistage erosion and infill of buried Pleistocene tunnel valleys and associated seismic velocity effects, Geol. Soc., London, Spec. Publ., 368, 159-172.

Kristensen, T.B., Piotrowski, J.A., Huuse, M., Clausen, O.R. \& Hamberg, L., 2008. Time-transgressive tunnel valley formation indicated by infill sediment structure, North Sea - the role of glaciohydraulic supercooling, Earth Surf. Process. Landf., 33, 546-559.

Lagarias, J.C., Reeds, J.A., Wright, M.H. \& Wright, P.E., 1998. Convergence Properties of the Nelder-Mead simplex method in low dimensions, SIAM J. Optim., 9, 112-147.

Lee, J.R., Candy, I. \& Haslam, R., 2018. The Neogene and Quaternary of England: landscape evolution, tectonics, climate change and their expression in the geological record, Proc. Geologists' Assoc., 129, $452-481$.

Le Maire, P. \& Munschy, M., 2018. 2D potential theory using complex algebra: new equations and visualization for the interpretation of potential field data, Geophysics, 83, J1-J13.

Lindner, H., Pretzschner, C., Kappler, R., Kritzner, W. \& Fritzsche, B., 2000. Exploration of Quaternary channels inside the town of Gorlitz by gravity measurements, in Proceedings 6th Meeting Environmental and Engineering Geophysics.

Lonergan, L., Maidment, S.C.R. \& Collier, J.S., 2006. Pleistocene subglacial tunnel valleys in the central North Sea basin: 3-D morphology and evolution, J. Quat. Sci., 21, 891-903.

Mackey, T. et al., 2000. Palaeochannels near West Wyalong, New South Wales: a case study in delineation and modelling using aeromagnetics, Explor: Geophys., 31, 1-7.

Martelat, J.-E., Randrianasolo, B., Schulmann, K., Lardeaux, J.-M. \& Devidal, J.-L., 2014. Airborne magnetic data compared to petrology of crustal scale shear zones from southern Madagascar: a tool for deciphering magma and fluid transfer in orogenic crust, J. Afr. Earth Sci., 94, 74-85.

MathWorks, MATLAB 2015. SIMULINK for technical computing. http: //www.mathworks.com 
Maystrenko, Y.P., Olesen, O., Ebbing, J. \& Nasuti, A., 2017. Deep structure of the northern North Sea and southwestern Norway based on 3D density and magnetic modelling, Norw. J. Geol., 97, 169-210.

Moreau, J., Huuse, M., Janszen, A., van der Vegt, P., Gibbard, P.L. \& Moscariello, A., 2012. The glaciogenic unconformity of the southern North Sea, in Glaciogenic Reservoirs and Hydrocarbon Systems, Vol. 368, pp. 99-110, eds Huuse, M., Redfern, J., Le Heron, D., Dixon, R.J., Moscariello, A. \& Craig, J., Geological Society of London.

Mørk, M.B.E., McEnroe, S.A. \& Olesen, O., 2002. Magnetic susceptibility of Mesozoic and Cenozoic sediments off Mid Norway and the role of siderite: implications for interpretation of high-resolution aeromagnetic anomalies, Mar. Pet. Geol., 19, 1115-1126.

Nabighian, M.N., 1972. The analytic signal of two-dimensional magnetic bodies with polygonal cross-section; its properties and use for automated anomaly interpretation, Geophysics, 37, 507-517.

Oasis montaj, 2018. GM-SYS Profile Modelling v 9.4.1 [Computer software]. Retrieved from www.geosoft.com

Olesen, O. et al., 2010. New aeromagnetic and gravity compilations from Norway and adjacent areas: methods and applications, Geol. Soc., London, Pet. Geol. Conf. Ser., 7, 559-586.

Ottesen, D., Batchelor, C.L., Dowdeswell, J.A. \& Løseth, H., 2018. Morphology and pattern of Quaternary sedimentation in the North Sea Basin $\left(52-62^{\circ} \mathrm{N}\right)$, Mar. Pet. Geol., 98, 836-859.

Ottesen, D., Dowdeswell, J.A. \& Bugge, T., 2014. Morphology, sedimentary infill and depositional environments of the Early Quaternary North Sea Basin $\left(56^{\circ}-62^{\circ} \mathrm{N}\right)$, Mar. Pet. Geol., 56, 123-146.

Ottesen, D. et al., 2016. Landform assemblages and sedimentary processes along the Norwegian Channel Ice Stream, Sediment. Geol., 338, 115-137.

Parker Gay, J.R., 2004. Glacial till: a troublesome source of near-surface magnetic anomalies, Appl. Geophys., 23, 513-616.

Praeg, D., 1996. Morphology, stratigraphy and genesis of buried midPleistocene tunnel-valleys in the southern North Sea Basin, PhD thesis, University of Edinburgh.

Rasmussen, E.S., Vejbaek, O.V., Bidstrup, T., Piasecki, S. \& Dybkjaer, K., 2005. Late Cenozoic depositional history of the Danish North Sea Basin: implications for the petroleum systems in the Kraka, Halfdan, Siri and Nini fields, in Petroleum Geology: North-West Europe and Global Perspectives, pp. 1347-1358, eds Doré, A.G. \& Vining, B.A..

Riis, F., 1996. Quantification of Cenozoic vertical movements of Scandinavia by correlation of morphological surfaces with offshore data, Glob. Planet. Change, 12, 331-357.
Sandersen, P.B.E., JøRgensen, F., Larsen, N.K., Westergaard, J.H. \& Auken, E., 2009. Rapid tunnel-valley formation beneath the receding Late Weichselian ice sheet in Vendsyssel, Denmark, Boreas, 38, 834-851.

Sejrup, H.P. et al., 1987. Quaternary stratigraphy of the Fladen area, central North Sea: a multidisciplinary study, J. Quat. Sci., 2, 35-58.

Steuer, A., Siemon, B. \& Auken, E., 2009. A comparison of helicopter-borne electromagnetics in frequency- and time-domain at the Cuxhaven valley in Northern Germany, J. Appl. Geophys., 67, 194-205.

Stewart, M., Lonergan, L. \& Hampson, G., 2012. 3D seismic analysis of buried tunnel valleys in the Central North Sea: tunnel valley fill sedimentary architecture, Geol. Soc., London, Spec. Publ., 368, 173-184.

Stewart, M.A. \& Lonergan, L., 2011. Seven glacial cycles in the middlelate Pleistocene of northwest Europe; geomorphic evidence from buried tunnel valleys, Geology, 39, 283-286.

Stewart, M.A., Lonergan, L. \& Hampson, G., 2013. 3D seismic analysis of buried tunnel valleys in the central North Sea: morphology, cross-cutting generations and glacial history, Quat. Sci. Rev., 72, 1-17.

Stoker, M.S., Skinner, A.C., Fyfe, J.A. \& Long, D., 1983. Palaeomagnetic evidence for early Pleistocene in the central and northern North Sea, Nature, 304, 332-334.

Talwani, M. \& Heitzler, J.R., 1964. Computation of magnetic anomalies caused by two dimensional structures of arbitrary shape, in Computers in the Mineral Industries, pp. 464-480, ed Parks, dans G.A., School of Earth Sciences, Stanford University Publications.

Thompson, D.T., 1982. EULDPH: a new technique for making computerassisted depth estimates from magnetic data, Geophysics, 47, 31-37.

van der Vegt, P., Janszen, A. \& Moscariello, A., 2012. Tunnel valleys: current knowledge and future perspectives, Geol. Soc., London, Spec. Publ., 368, 75-97.

Weatherall, P. et al., 2015. A new digital bathymetric model of the world's oceans: new digital bathymetric model, Earth Space Sci., 2, 331-345.

Westaway, R., 2017. Isostatic compensation of Quaternary vertical crustal motions: coupling between uplift of Britain and subsidence beneath the North Sea: Quaternary vertical crustal motions: Britain and the North Sea, J. Quat. Sci., 32, 169-182.

Ziegler, P., 1990. Tectonic and palaeogeographic development of the North Sea rift system, in Tectonic Evolution of the North Sea Rifts, Oxford Science Publications, pp. 1-36.

Ziegler, P.A., 1992. European Cenozoic rift system, Tectonophysics, 208(13), 91-111. 